\title{
A revision of the genus Cicynethus Simon, 1910 (Araneae, Zodariidae), a tale of colour patterns
}

\author{
Rudy JOCQUÉ ${ }^{1, *}$ \& Arnaud HENRARD ${ }^{2, *}$ \\ ${ }^{1,2}$ Royal Museum for Central Africa, Leuvensesteenweg 13, B-3080 Tervuren, Belgium. \\ ${ }^{1}$ Biodiversity Inventory for Conservation (BINCO), Walmersumstraat 44, 3380 Glabbeek, Belgium. \\ ${ }^{2}$ Earth and Life Institute, Biodiversity Research Center, UCL-17. 07. 04, Bâtiment Carnoy, \\ Croix du Sud, 5, B-1348, Louvain-la-Neuve, Belgium. \\ *Corresponding authors: rudy.jocque@africamuseum.be; arnaud.henrard@africamuseum.be; \\ arnaud.henrard@gmail.be \\ ${ }^{1}$ urn:1sid:zoobank.org:author:CF15016C-8CD1-4C9D-9021-44CA7DC7A5D5 \\ ${ }^{2}$ urn:lsid:zoobank.org:author:E1B02E6E-D91C-43FE-8D8C-CD102EFEE3B4
}

\begin{abstract}
The genus Cicynethus Simon, 1910 is revised. Apart from the type species C. peringueyi Simon, 1893, only known from a juvenile, it contains five species, all of which are here described or redescribed based on adults: $C$. acer sp. nov. (§o+), C. decoratus (Lawrence, 1952) comb. nov (đ),

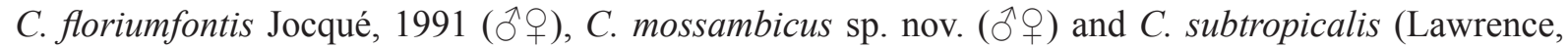
1952) comb. nov. ( $\$$ ) ). The species are characterized by the genitalia, but also by the colour pattern. The distribution of the genus is extended to northern Mozambique. Cicynethus hongfuchui is transferred to Storenomorpha hongfuchui (Barrion, Barrion-Dupo \& Heong, 2013) comb. nov. Cicynethus acanthopus Simon, 1910 is considered a species incertae sedis. A key to the species is provided.
\end{abstract}

Keywords. Range extension, southern Africa, Storenomorphinae.

Jocqué R. \& Henrard A. 2018. A revision of the genus Cicynethus Simon, 1910 (Araneae, Zodariidae), a tale of colour patterns. European Journal of Taxonomy 465: 1-35. https://doi.org/10.5852/ejt.2018.465

\section{Introduction}

The faunistic approach of taxonomy, that prevailed into the mid sixties of the previous century, led to many misplaced species and synonymies as explained in Platnick \& Raven (2013). Consequently, the spider family Zodariidae was also riddled with nomenclatorial problems and insufficiently described genera before the revision by Jocqué (1991). Many genera were only known from juveniles (e.g., Systenoplacis Simon, 1907, Hetaerica Rainbow, 1916), sometimes leading to unnecessary synonymies (see Jocqué 2009).

A perfect example in this respect is the genus Cicynethus Simon, 1910 that, at the time of the family revision (Jocqué 1991), was only known from two species, both exclusively represented by juveniles. The redescription (Jocqué 1991) was based on a single male only and females have still not been described for these species. The present paper aims to redefine the genus, this time based on both sexes, correct the misplacement of a few species, including the species from China, and describe two new species, thereby considerably expanding the distribution of the genus in Africa. 


\section{Material and methods}

Specimens were observed, drawn and measured with a WILD M 10 stereo microscope. Details of the female genitalia and male palps were observed with a Zeiss Stemi 2000 stereo microscope. Female genitalia were digested using half a tablet of Total Care Enzima product (protein removal system originally for cleaning contact lenses and containing subtilisin A, $0.4 \mathrm{mg}$ per tablet; Abbott Medical Optics, Santa Ana, CA) in a few millilitres of distilled water overnight and then immersed in $75 \%$ ethanol. Photographs of these female genitalia and male palps, as well as measurements and photographs of the habitus and details of mouthparts were taken with a Leica MZ16 A using the Leica Application Suite (LAS) automontage software (ver. 3.8). The habitus of some specimens was photographed by the focus stacking technique developed at the Royal Museum for Central Africa (part of the Digit 03 project) and explained in Brecko et al. (2014). For SEM photos, specimens were air dried (36 h), gold coated, examined and photographed with a JEOL $6480 \mathrm{LV}$ scanning electron microscope. Illustrations were assembled and edited in Photoshop CS5 (white balance and colour contrast adjusted). Maps were created with the online tool SimpleMappr (Shorthouse 2010).

Types of the new species are deposited in the National Collection of Arachnids (Pretoria, South Africa) (NCA), the Ditsong National Museum of Natural History (TMSA, former Transvaal Museum) and the Royal Museum for Central Africa, Tervuren, Belgium (RMCA).

All palp illustrations are from left palps unless stated otherwise. All measurements are in mm unless otherwise indicated.

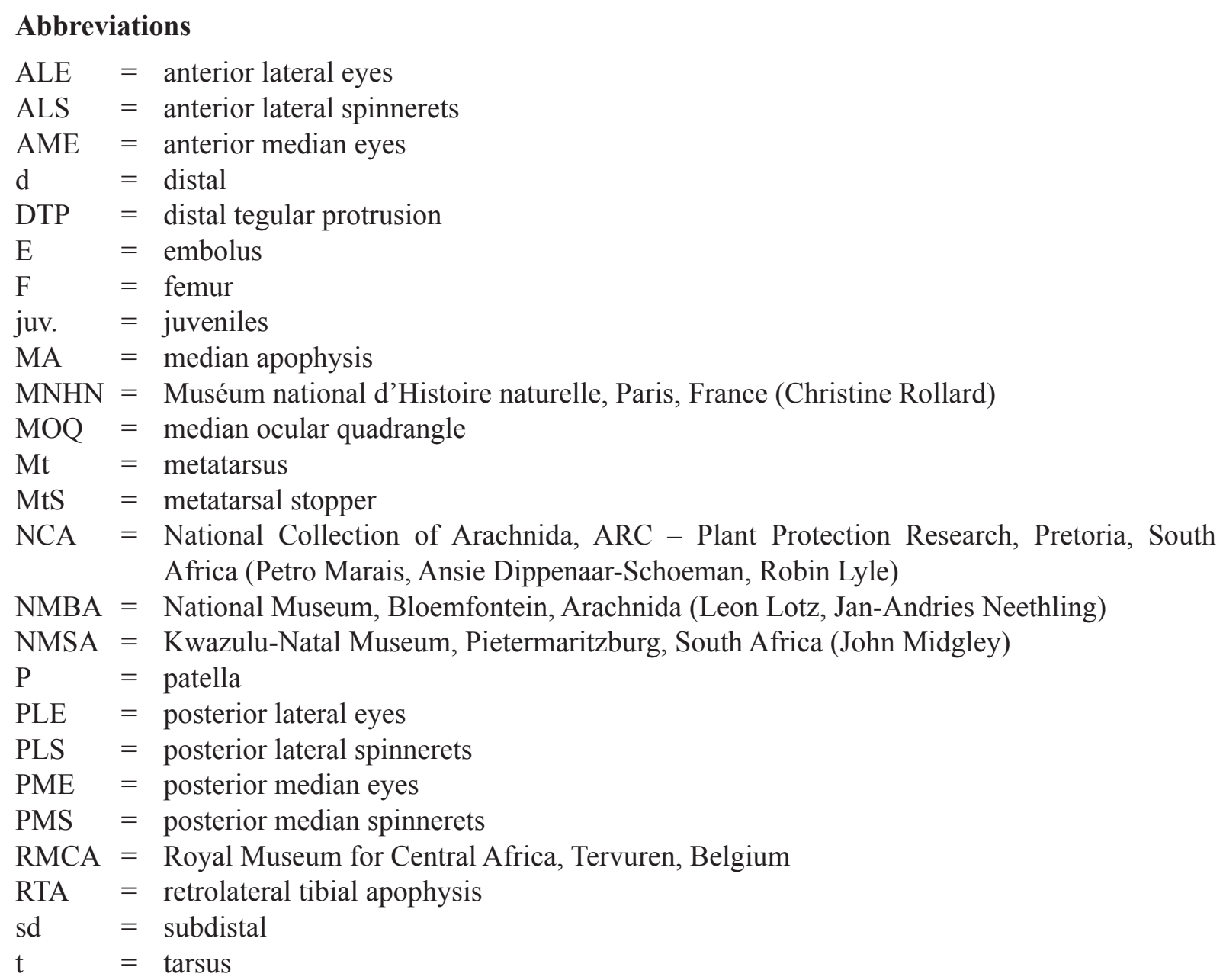


$\mathrm{T} \quad=$ tibia

TMSA = Transvaal Museum, Pretoria, South Africa (now Ditsong National Museum of Natural History)

\title{
Results
}

\author{
Class Arachnida Cuvier, 1812 \\ Order Araneae Clerck, 1757 \\ Family Zodariidae Thorell, 1881 \\ Subfamily Storenomorphinae Simon, 1890
}

Genus Cicynethus Simon, 1910

\section{Type species}

Cicynethus peringueyi Simon, 1893 (known from juvenile only).

\section{Diagnosis}

Cicynethus are medium-sized, elongated spiders with eyes in two procurved rows and spination on legs reduced to a few small distal spines on the ventral side of the metatarsi. It differs from Chariobas Simon, 1893, which has the eyes in a close group, and from Thaumastochilus Simon, 1897, which has strong spines on the anterior leg pair.

\section{Description}

Body. Medium-sized to large spiders $(9.2-14.4 \mathrm{~mm})$ with smooth to finely granulate teguments. Carapace longer than wide (L/W < 1.5-2.2) and fairly flat, protruding anteriorly (Figs 12B, 16D), widest at level of coxae II-III, not much narrowed in front to about 0.6-0.65 times maximum width (cephalic width measured on strong frontal bend), with few hairs apart from a few longer hairs in front of fovea and on clypeus. Cervical grooves faint. Profile highest just behind eyes and with slight dip at level of fovea.

Colour. Carapace medium to dark brown; chelicerae, mouthparts and sternum medium to orange brown; leg colour complex, frontal legs often darker and more uniform than posteriors; abdomen dorsum grey with species-specific colour pattern. Remark: colour pattern often darker in vivo (Fig. 15A-B), much more contrasted in alcohol.

EYEs. Eyes in two procurved rows (Fig. 5C). All eyes pale and subequal, AME usually the largest. MOQ quadrangular or slightly longer than wide. Clypeus straight, height 0.8 to 2 times diameter of ALE, with dispersed setae.

Prosoma. Chilum double, poorly sclerotized, about or slightly more than twice as wide as high, lateral margin poorly defined, with a few setae. Chelicerae without teeth, broad from base to tip with evenly dispersed setae; fangs shorter than wide at base. Labium diamond-shaped, widest in distal half, narrowed base. Endites roughly triangular, converging, with basolateral extension accommodating palpal coxa; with field of thick setae in distal half. Sternum elongated, roughly oval (Figs 8C, 9B, E, 12D), longer than wide, widest at middle, without triangular extensions; sometimes with a few precoxal sclerites (Fig. 16B); anterior margin straight or slightly concave.

Legs. Fairly slender, anterior legs more robust than posterior ones. Formula 1243 or 1423. Spination reduced to a few short ventral spines on Mt, arranged as 1-3 along distal margin and 1 or 2 subdistal behind the middle distal one. Paired tarsal claws with 10-14 teeth (Fig. 1A); unpaired claw smooth, strongly reduced on hind legs. Tarsal organ capsulate (Fig. 1E). Scopulae well developed. Metatarsi with 
distal hood (MtS) extended to ventrolateral side (Fig. 1C). Tibial process well developed (Fig. 1D). One dorsal hinged hair on tibiae and metatarsi I and II. Bothria with one ridge (Fig. 1F-G).

Female Palp. Female palpal tarsus conical, with short but strong prolateral spines (Fig. 8D); palpal claw with some small teeth at base (Fig. 1B); not turned inward; without distal patch of chemosensitive setae.

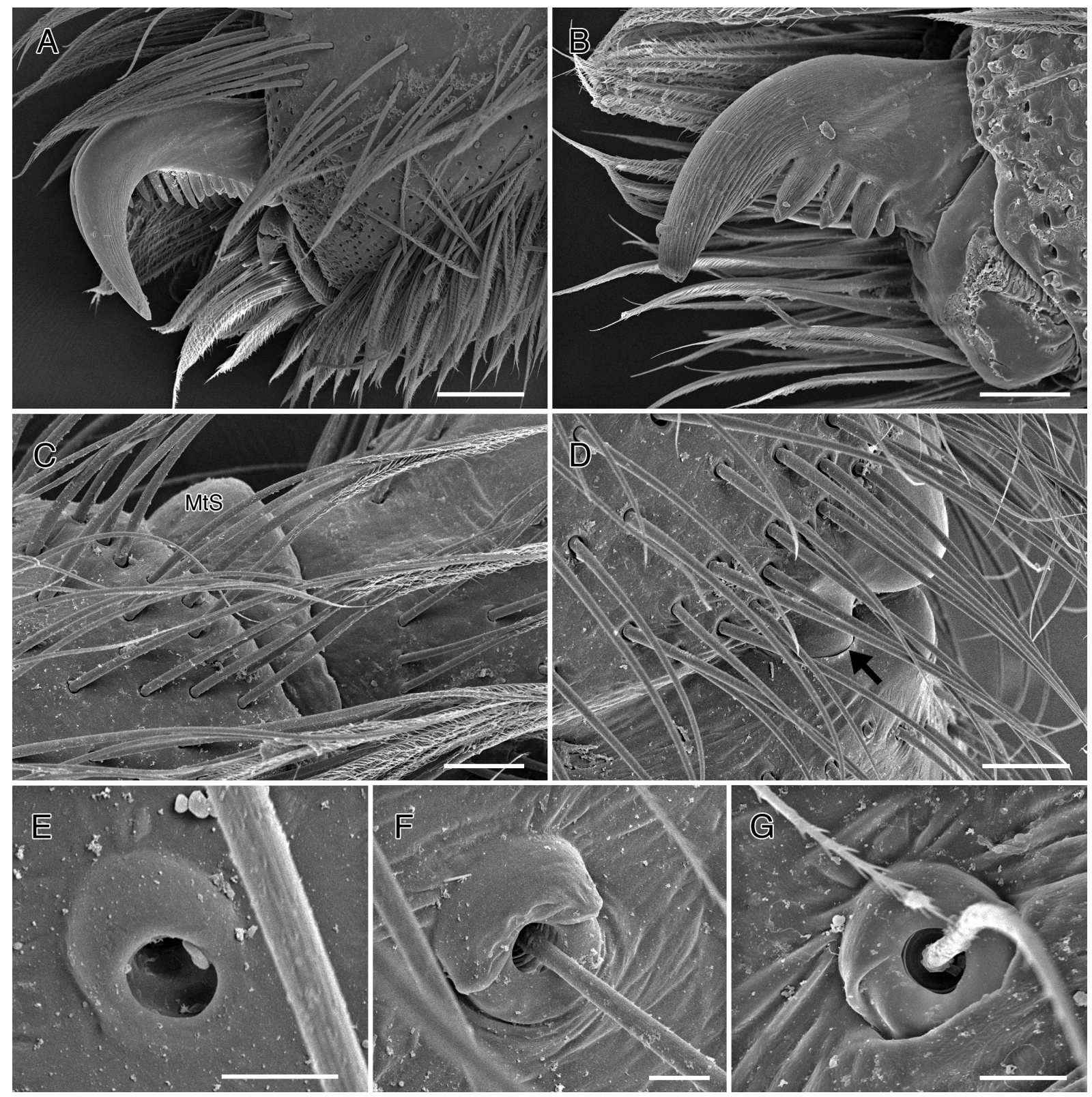

Fig. 1. SEM micrographs of Cicynethus subtropicalis (Lawrence, 1952) comb. nov. A-E. $q$ (NCA 2000/438). F-G. O (NCA 2008/4266). A. Paired tarsal claw II, retrolateral view. B. Palpal claw, prolateral view. C. Metatarsus II, apex, showing metatarsal stopper (MtS). D. Tibial process (arrow), left leg IV, dorsal view. E. Tarsal organ, leg IV, dorsal view. F. Bothrium, metatarsus IV, dorsal view. G. Trichobothrium, base of RTA, retrolateral view. Abbreviation: $\mathrm{MtS}=$ metatarsal stopper. Scale bars: $\mathrm{A}=0.1 \mathrm{~mm} ; \mathrm{B}-\mathrm{D}=50 \mu \mathrm{m} ; \mathrm{E}-\mathrm{G}=10 \mu \mathrm{m}$. 
AвDOMEN. Elongated oval or cylindrical, at least twice as long as wide; tracheal spiracle fairly small, somewhat advanced and provided with small rectangular scutellum. Both sexes with six spinnerets. ALS large, conical, biarticulate. PLS cylindrical, biarticulate, with 4 cylindrical gland spigots; PMS small, cylindrical, one-segmented with 2 cylindrical gland spigots. Colulus represented by haired field.

MaLe PaLP. Structure of male palp stable; RTA characteristic, with broad and long basal shaft ending in widened tip with two blades often perpendicular to each other (Fig. 2A-H). Cymbium without distal claw (Fig. 2A, D), with a few distal, slightly sinuous truncated spines (Figs 3F, 6B); tegulum often strongly swollen; embolus fairly short, originating prolaterally on posterior part of tegulum (Figs 2D, 3F, 6B); MA strongly curved outwards (Figs 3F, 6B).

EPIGYNE. With two central depressions separated by septum, in front of transverse plate (Figs 4E, 7D-H). Spermathecae large, reniform, far apart (Fig. 13F); copulatory ducts short, with thick walls.

\section{Natural history}

See the Discussion for the few observations concerning the habits of species of Cicynethus.

\section{Distribution}

Cicynethus is found in South Africa and Mozambique, with its northernmost locality in the Nyassa Province of Mozambique (Figs 21-22).

\section{Species included}

Cicynethus acer sp. nov. (ぷ+)

Cicynethus decoratus (Lawrence, 1952) comb. nov. (ㅇ)

Cicynethus floriumfontis Jocqué, 1991 (đ̋+

Cicynethus mossambicus sp. nov. (ð゚ㅇ)

Cicynethus peringueyi Simon, 1893 (juveniles)

Cicynethus subtropicalis (Lawrence, 1952) comb. nov. (ð゚)

Key to the species (specimens in ethanol; C. peringueyi not included)

1. Cephalothorax uniformly dark chestnut brown, with small reddish spot in front of posterior margin (Fig. 12A, C); legs covered with numerous long hairs (Fig. 12A-D); male palpal bulbus, with well developed distal tegular protrusion (DTP), without retrolateral boss and not strongly swollen (Figs 2D, 13A-B); epigyne with thick transverse plate and short, well-defined thick median septum (Fig. 13D-F) C. mossambicus sp. nov.

- Cephalothorax differently coloured and with pattern; legs covered with shorter hairs; male palpal bulbus strongly swollen (Figs 2A, F-G, 10A-B, 18A, C-D, F) or with retrolateral boss (Figs 3D-F, 6A-B), DTP reduced or inconspicuous; epigyne with transverse plate narrower and with longer or faint median septum.

2. Entire body yellowish brown; base of setae with black spots throughout; legs spotted and with stripes on femora and patellae (Fig. 9A-F)

- Differently coloured; base of setae without black spots; leg pattern different

3. Abdomen dorsum with large anterior diamond-shaped spot, without white longitudinal stripe in front of spinnerets (Fig. 7A-C); femora (F) and tibiae (T) II-IV with black ring (Fig. 8B) C. decoratus (Lawrence, 1952) comb. nov.

- Abdomen dorsum with simple longitudinal median stripe ending in short white stretch in front of spinnerets (Figs 3A, 4A-B, 5A, 15A-G); F and T without ring 

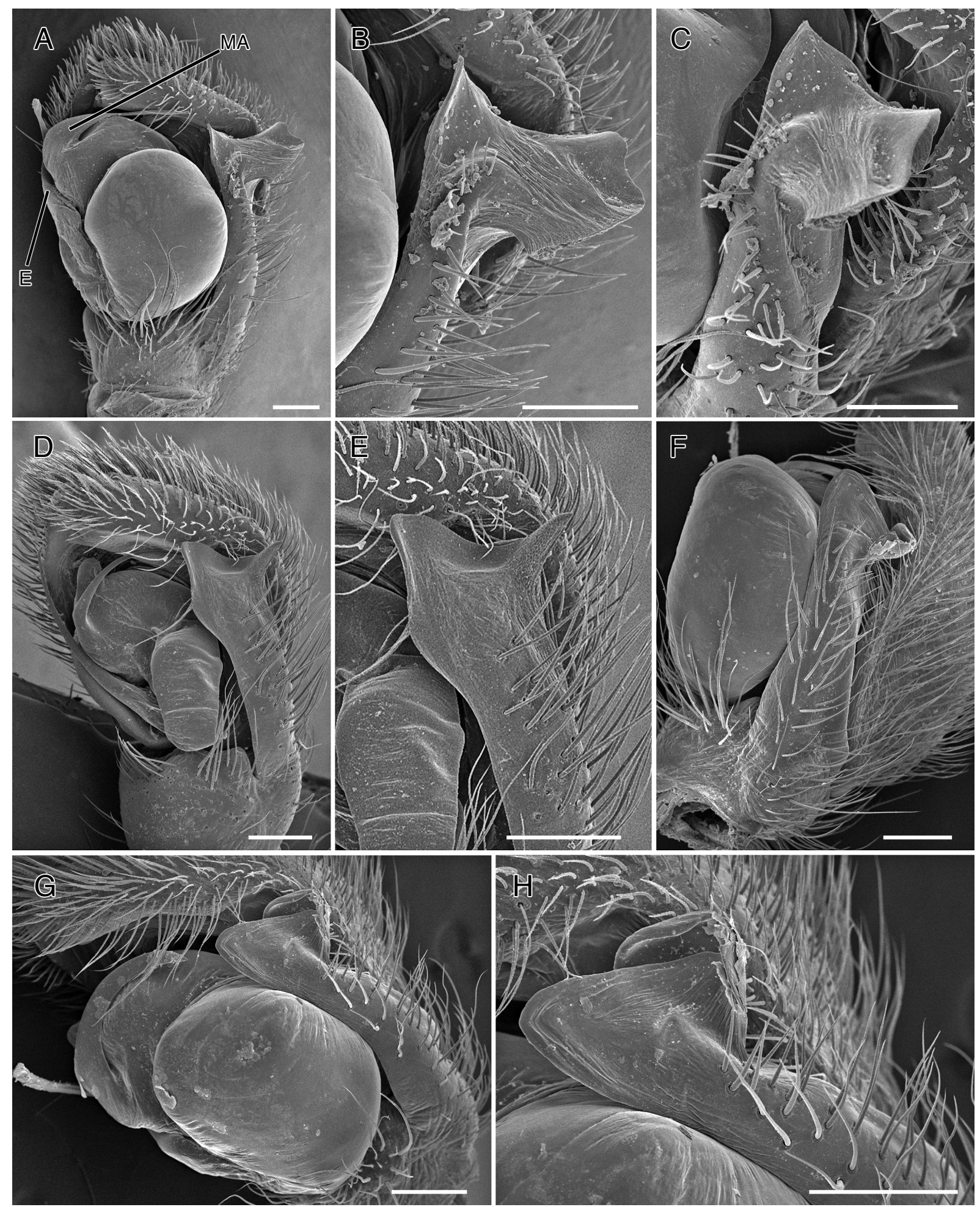

Fig. 2. SEM micrographs of male palps and RTA. A-C. Cicynethus floriumfontis Jocqué, 1991, ô (NCA 91/1051). D-E. C. mossambicus sp. nov., Ô (RMCA_ARA_245567). F-H. C. subtropicalis (Lawrence, 1952) comb. nov., ô (NCA 2008/4266). A. Male palp, ventro-retrolateral view. B. RTA apex, ventroretrolateral view. C. As preceding, retrolateral view. D. Male palp, ventro-retrolateral view. E. RTA apex, ventro-retrolateral view. F. Male palp, retrolateral view. G. As preceding, ventro-retrolateral view. H. RTA apex, ventro-retrolateral view. Abbreviations: $\mathrm{E}=$ embolus; $\mathrm{MA}=$ median apophysis. Scale bars: $0.2 \mathrm{~mm}$. 
4. Tip of RTA with sharp dorsal appendage (Fig. 3F); tegulum not strongly swollen, but with retrolateral boss (Fig. 3D-F); MA smoothly curved; embolus long, almost reaching distal tip of cymbium (Fig. 3F); epigyne with well defined, Y-shaped median septum (Figs 4E, 6C) ......... C. acer sp. nov. - Palp with dorsal excrescence of RTA tip flat, lamellar; tegulum strongly swollen and bulging (Fig. 18A, C-D, F); MA frontal margin with boss; embolus reaching distal margin of cymbial alveolus; epigyne with faint median septum (Fig. 17A-H)

C. subtropicalis (Lawrence, 1952) comb. nov.

\author{
Cicynethus acer sp. nov. \\ urn:lsid:zoobank.org:act:227C79D9-B0F1-42EF-9D74-A9BFAB78873B
}

Figs 3-6, 21

\title{
Diagnosis
}

The male of Cicynethus acer sp. nov. is recognized by the sharp excrescence at the tip of the RTA and the retrolateral knob on the tegular swelling. The epigyne is similar to that of $C$. floriumfontis, but the median septum is provided with two conspicuous anterior arches in the latter.

\section{Etymology}

The species name 'acer' is an adjective meaning 'sharp' and referring to the sharp excrescence of the RTA.

\section{Material examined}

Holotype

SOUTH AFRICA: $\hat{O}^{\lambda}$, MpumAlanga Province, Pilgrim's Rest, Mariepskop, 2432' S, 3052’ W, 25 Nov. (no year but before 1990), G. Van Dam leg. (TM 6162).

\section{Paratypes}

SOUTH AFRICA: $1 \hat{\alpha}$, together with holotype; 1 q, Limpopo Province, Pietersburg (now Polokwane) $23^{\circ} 54^{\prime}$ S, $27^{\circ} 23^{\prime}$ E, 4 Nov. 1916, C.A. Thompson leg. (TM 13375; formerly 2217).

\section{Other material}

SOUTH AFRICA: 2 juv., MpumAlanga Province, Pilgrim's Rest, forest of Mariepskop, $24^{\circ} 32^{\prime}$ S, 3052' E, Aug. 1960, in humus, N. Leleup leg. (RMCA_ARA_131816).

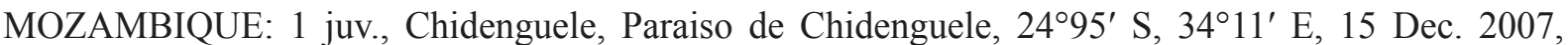
beating shrubs, dune forest, R. Lyle, C. Haddad and R. Fourie leg. (RMCA_ARA_223066; DNA Z130).

\section{Description}

Holotype (male)

MEASUREMENTS. Total length: 10.30. Carapace: length 4.62, width 2.63, height 1.35.

Colour (Fig. 3A-C). Carapace medium reddish brown, darker on sides, with paler median spot near posterior margin and central dark band in front of fovea, widened behind and reaching ocular area; chelicerae medium brown with pale mediodistal patch; sternum medium brown, paler towards posterior, pale yellow tip, darker along margins; endites and labium pale yellow, darker along margins; legs pale yellow with all P medium brown on sides; leg I with distal half of T, Mt and t medium brown; leg II with Mt and t brownish yellow, legs III and IV with distal part of Mt and t brownish yellow; abdomen: dorsum with dark grey mottling provided with two median triangles and white median stripe in front of spinnerets; sides with dark grey mottling; venter pale with poorly defined dark stripes in posterior half.

Sternum (Fig. 3B). Elongated oval, 1.42 wide, 2.06 long. No precoxal sclerites.

Chilum. Two sclerites 0.10 high, 0.25 wide, with few setae. 
EYes. AME larger than other eyes: ALE 0.20; AME 0.16; PLE 0.15; PME 0.15; ALE-AME 0.10; AMEAME 0.07; PLE-PME 0.15; PME-PME 0.08. Clypeus 0.28 high.

Leg SPINATION. With distal ventral spines MT I: D2 sD1; MT II: D2 sD1; MT III: D3 SD2; MT IV: D3 SD3.

LEG MEASUREMENTS.

\begin{tabular}{ccccccc}
\hline & Fe & P & Ti & Mt & t & Total \\
\hline I & 2.94 & 1.47 & 2.80 & 1.82 & 1.12 & 10.15 \\
II & 2.45 & 1.26 & 2.52 & 1.68 & 1.05 & 8.96 \\
III & 1.96 & 1.19 & 1.40 & 1.26 & 0.84 & 6.65 \\
IV & 2.80 & 1.26 & 2.17 & 1.75 & 1.12 & 9.10 \\
\hline
\end{tabular}

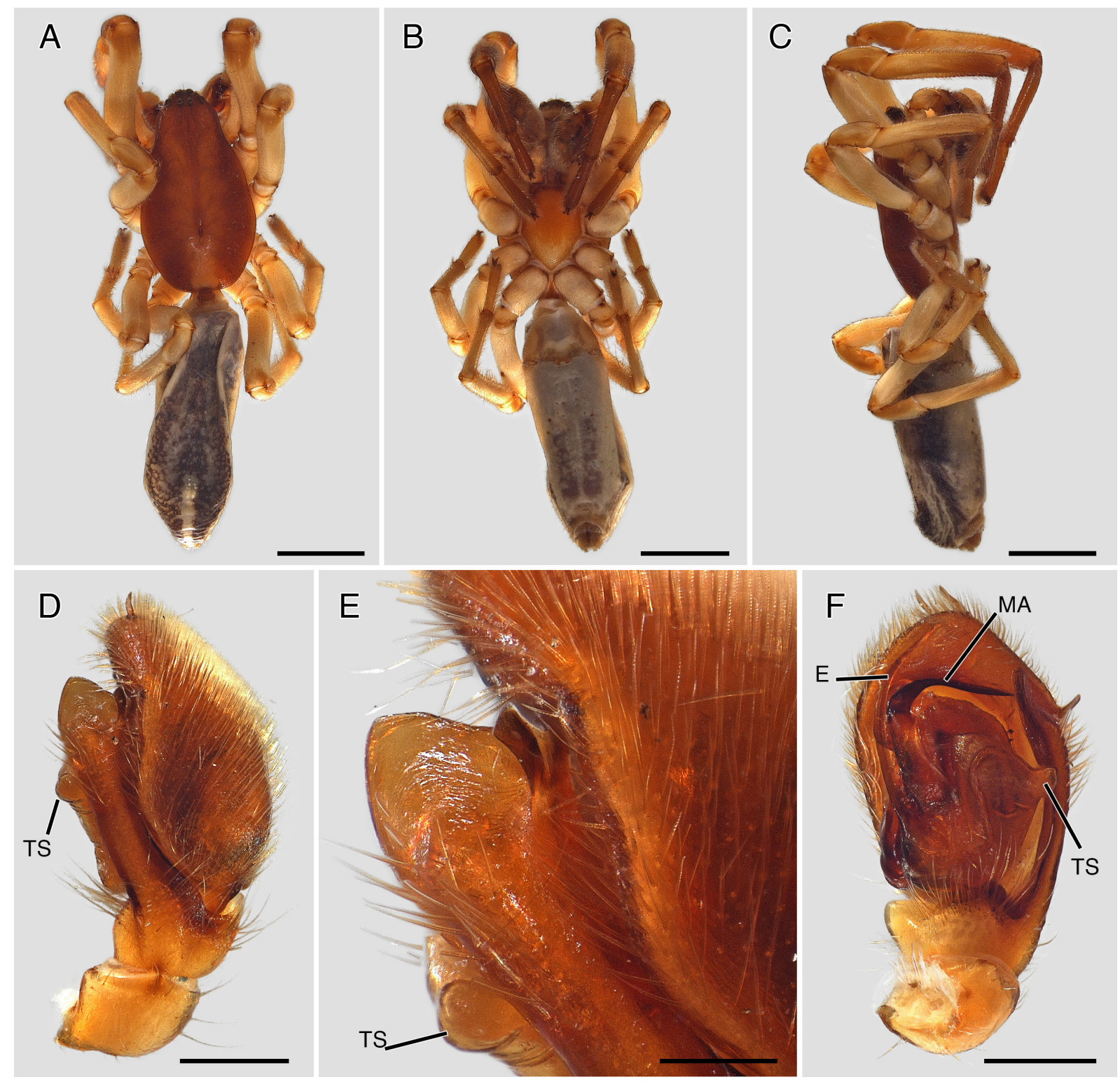

Fig. 3. Cicynethus acer sp. nov., holotype, $ð$ (TM 6162). A. Habitus, dorsal view. B. As preceding, ventral view. C. As preceding, lateral view. D. Palp, retrolateral view. E. As preceding, detail of RTA. F. Palp, ventral view. Abbreviations: $\mathrm{E}=$ embolus; $\mathrm{MA}=$ median apophysis; $\mathrm{TS}=$ tegular swelling. Scale bars: A-C $=5 \mathrm{~mm} ; \mathrm{D}, \mathrm{F}=0.5 \mathrm{~mm} ; \mathrm{E}=0.2 \mathrm{~mm}$. 
LEGs. Mt I and II with four distal ventral spines in a series 1-3 with central ones closely set behind each other, Mt III with 2-3 and IV with 3-3.

MALE PALP (Figs 3D-F, 6A-B). RTA broad and straight, widened at tip with narrow lamellate extension pointing up and outward, with sharp tip in ventral view; tegulum with central swelling itself with retrolateral knob; embolus slightly curved, long, almost reaching tip of cymbium; MA sharply curved outward, distal section straight.

Paratype (female)

MeAsurements. Total length: 17.04. Carapace: length 4.97, width 2.98, height 1.56.
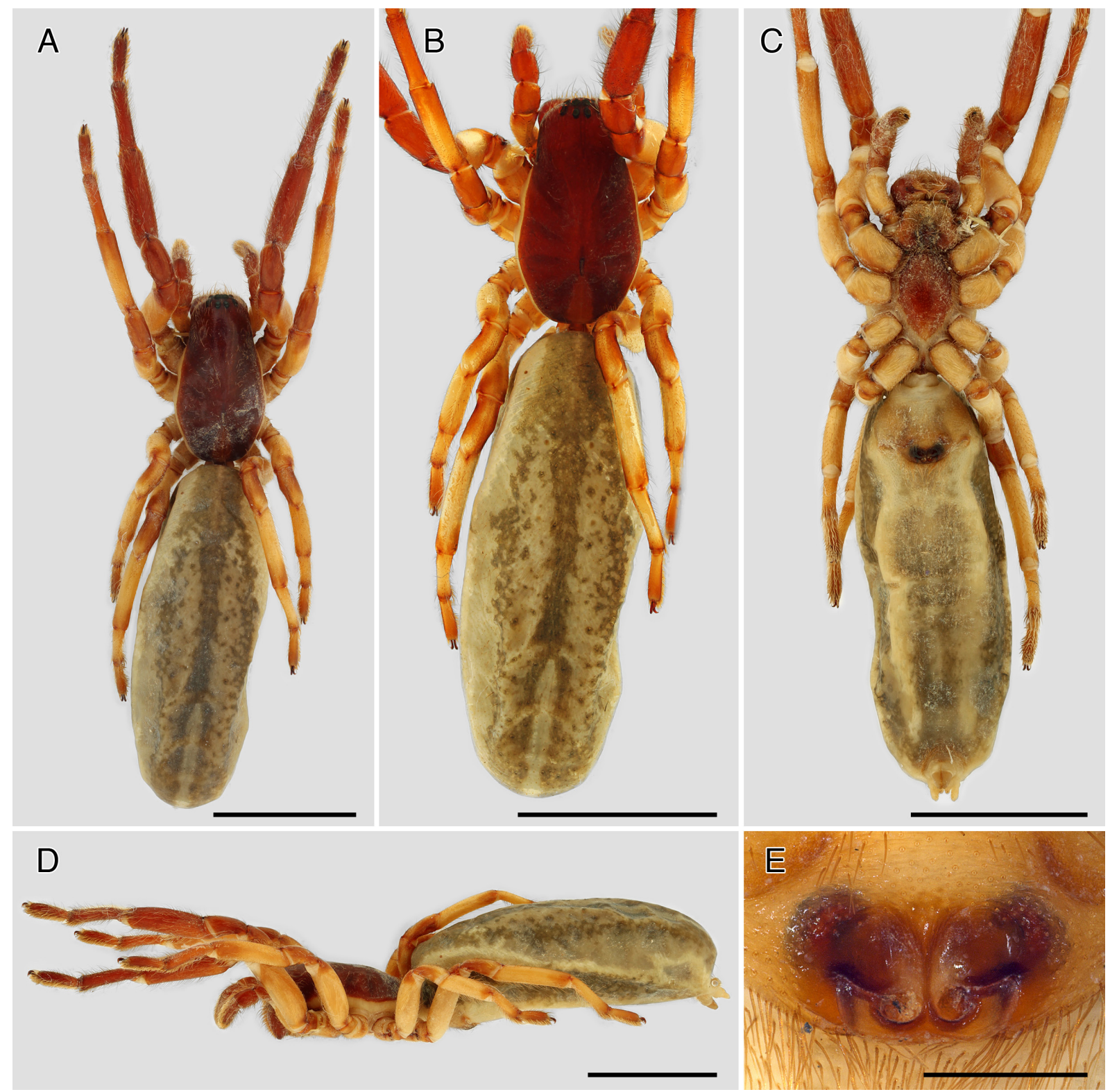

Fig. 4. Cicynethus acer sp. nov., paratype, $ᄋ$ (TM 13375). A. Habitus, dorsal view. B. As preceding, closer view. C. As preceding, ventral view. D. As preceding, lateral view. E. Epigyne, ventral view. Scale bars: $\mathrm{A}-\mathrm{D}=5 \mathrm{~mm} ; \mathrm{E}=0.2 \mathrm{~mm}$. 
Colour (Fig. 4A-D). Carapace uniform reddish brown, with paler triangle behind fovea reaching posterior margin. Chelicerae reddish brown, with pale patch near fangs. Endites reddish brown at base, fading to yellowish in front; labium reddish brown, paler in front. Sternum uniform dark reddish brown, paler near posterior tip. Legs I with F yellow, distal part and remainder of legs orange; legs II yellow, with distal orange rings on $\mathrm{F}$ and $\mathrm{T}$ orange, $\mathrm{P}$, Mt and t orange; legs III-IV yellow, with narrow distal ring on $\mathrm{F}, \mathrm{T}$ and $\mathrm{Mt}$; entire $\mathrm{P}$ and distal part of $\mathrm{t}$ orange. Abdomen pale with three longitudinal dark stripes, the central one with two faint triangles in front of white longitudinal bar; sides dark mottled grey; venter with two ill-defined longitudinal stripes.

Sternum (Fig. 4C). Elongated oval, 1.49 wide, 2.41 long. Precoxal sclerites in front of coxae II poorly delimited.

Eyes. ALE 0.18; AME 0.18; PLE 0.16; PME 0.16; ALE-AME 0.07; AME-AME 0.08; PLE-PME 0.21; PME-PME 0.12. Clypeus 0.36 high.

Leg spination. With distal ventral spines Mt I: d2; Mt II: d2 sd1; Mt III: d2 sd1; Mt IV: d2 sd1-1.

LEG MEASUREMENTS.

\begin{tabular}{ccccccc}
\hline & Fe & P & Ti & Mt & t & Total \\
\hline I & 3.22 & 1.54 & 2.59 & 1.82 & 1.33 & 10.50 \\
II & 2.80 & 1.40 & 2.66 & 1.82 & 1.26 & 9.94 \\
III & 2.10 & 1.33 & 1.61 & 1.05 & 1.05 & 7.14 \\
IV & 2.66 & 1.54 & 2.24 & 1.61 & 1.19 & 9.24 \\
\hline
\end{tabular}

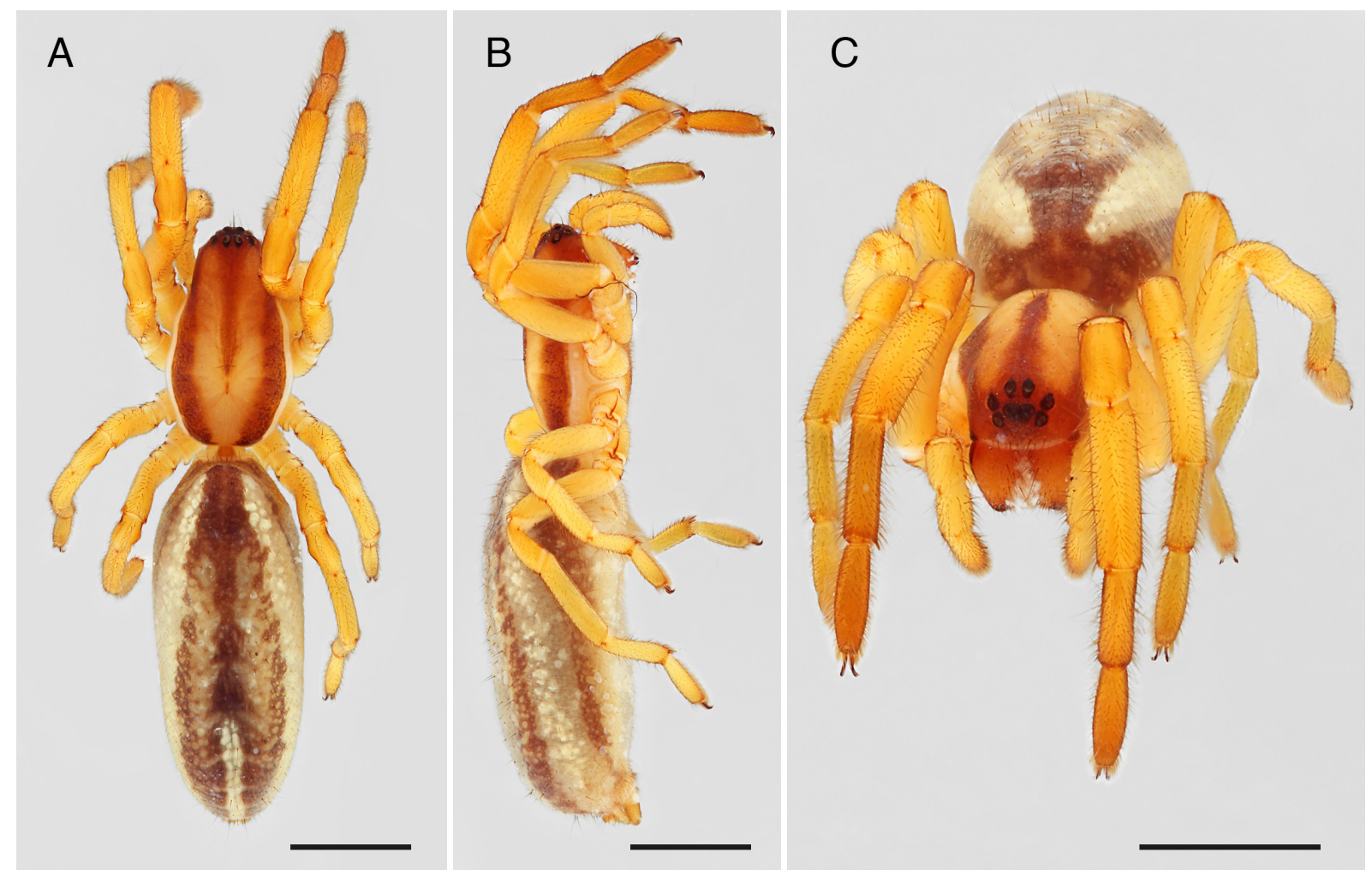

Fig. 5. Cicynethus acer sp. nov., juvenile (RMCA_ARA_131816). A. Habitus, dorsal view. B. As preceding, lateral view. C. As preceding, frontal view. Scale bars: $2 \mathrm{~mm}$ 
Epigyne (Figs 4E, 6C). With sclerotized, boat-shaped transverse bar delimiting longitudinal oval openings separated by well developed, narrow Y-shaped septum; anterior part of openings narrowed by dark brown, slightly swollen sclerotized area.

\section{Variation}

In the juveniles (Fig. 5A-C) the colour pattern is much more contrasted than in the adults. The carapace has three well-defined dark bands and in the median stripe of the dorsal abdominal pattern, the two triangles in front of the white bar are much more clearly marked than in the adults.

\section{Distribution}

Known from the type locality in northern MpumAlanga Province, from Limpopo Province and from southern Mozambique (Fig. 21).
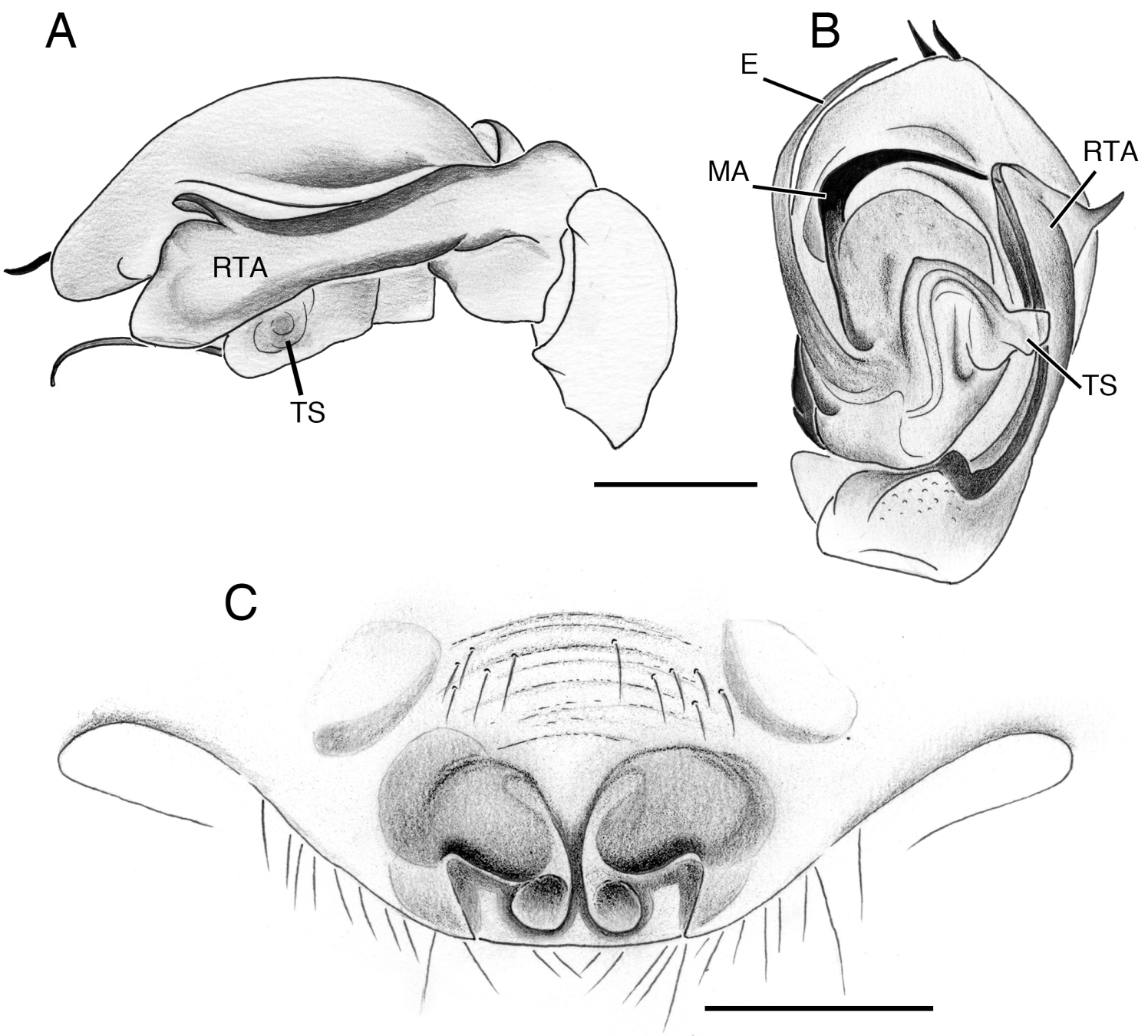

Fig. 6. Cicynethus acer sp. nov., genitalia drawings. A. Male palp, retrolateral view. B. As preceding, ventral view. C. Epigyne, ventral view. Abbreviations: $\mathrm{E}=$ embolus; $\mathrm{MA}=$ median apophysis; RTA = retrolateral tibial apophysis; TS = tegular swelling. Scale bars: $0.2 \mathrm{~mm}$. 
Cicynethus decoratus (Lawrence, 1952) comb. nov.

Figs 7-8, 21

Chariobas decorata Lawrence, 1952: 195, fig. 24 (descr. ㅇ).

\section{Diagnosis}

The female of Cicynethus decoratus comb. nov., is recognized by the epigyne with broad plate deeply indented in front and by the dark rings on the ventral part of all Fe and TII-IV.

\section{Material examined}

\section{Holotype}

SOUTH AFRICA: + , Kwazulu-Natal Province, Port Edward, $31^{\circ} 03^{\prime} \mathrm{S}, 30^{\circ} 13^{\prime}$ E, Nov. 1943, R. Lawrence and R. Holiday leg. (NM 3923).

\section{Other material}

SOUTH AFRICA: 1 + , Kwazulu-Natal Province, Oribi Gorge Nature Reserve, 30 40.791' S, $30^{\circ} 15.571^{\prime}$ E, sifting leaf litter, $450 \mathrm{~m}$ a.s.1., 13 Jan. 2011, C. Haddad leg. (NCA 2014/3298); 1 \%, Eastern Cape Province, Port St Johns District, Ingogo Forest Reserve, 31 ${ }^{\circ} 37^{\prime} \mathrm{S}, 2^{\circ} 32^{\prime} \mathrm{E}$, in humus, Dec. 1961, N. Leleup leg. (RMCA_ARA_131806); 1 , 16 juveniles, including subadult $\delta \hat{\delta}$ and $q$, same collection data as for preceding (RMCA_ARA_131933).

\section{Description}

\section{Holotype (female)}

MeAsurements. Total length: 12.57. Carapace: length 5.11, width 2.91, height 1.42.

Colour (Fig. 7A). Carapace reddish brown, with paler median spot near posterior margin. Chelicerae reddish brown with pale patch near fangs. Endites reddish brown fading to yellowish in front; labium dark reddish brown, paler in front. Sternum uniform dark reddish brown, darkened along anterior margins. Legs yellowish orange; anterior legs darker reddish brown from P onwards; F with dark ventral distal spot; d F II with dark distal ring interrupted dorsally; F II-IV with dark ring on distal third; all P darkened on sides; T II with basal dark ring; T II-IV with dark ring on distal third. Abdomen cream, dorsum with dark dorsal pattern: lateral bands with three ill-defined triangles and median band consisting of diamond, stripe, 2 chevrons and 2-segmented spot in front of spinnerets; sides with one large frontal spot and two small posterior ones; venter with two longitudinal dark lines.

Sternum. Elongated oval, 1.35 wide, 2.20 long. Precoxal sclerites in front of coxae II.

ChiLum. Two poorly defined triangles, each 0.09 high, 0.21 wide.

Eyes. ALE 0.18; AME 0.16; PLE 0.18; PME 0.16; ALE-AME 0.08; AME-AME 0.07; PLE-PME 0.16; PME-PME 0.08. Clypeus 0.30 high.

LEG MEASUREMENTS.

\begin{tabular}{ccccccc}
\hline & Fe & P & Ti & Mt & t & Total \\
\hline I & 3.48 & 2.36 & 3.34 & 2.85 & 2.43 & 9.5 \\
II & 3.13 & 2.36 & 2.99 & 2.57 & 2.22 & 8.31 \\
III & 2.78 & 2.15 & 2.15 & 2.01 & 1.94 & 6.07 \\
IV & 3.27 & 2.36 & 2.85 & 2.43 & 2.01 & 7.96 \\
\hline
\end{tabular}


Legs spination. With distal ventral spines Mt I: d3 sd1; Mt II: d3 sd1; Mt III: d2 sd1; Mt IV: d2 sd1-1.

EPIGYNe (Fig. 7D). With broad plate, longer in front; with deep median indentation, without median septum; frontal corners of plate surrounded by dark circular area.

Female (NCA 2014/3298)

MeAsurements. Total length: 9.23. Carapace: length 4.12, width 2.34, height 1.21.

CoLoun (Fig. 7B). Carapace reddish brown, slightly suffused with black in cephalic region, with narrow long dark ' $\mathrm{V}$ ' in front of fovea and four dark marginal triangles on either side. Chelicerae reddish brown with pale patch near fangs. Endites yellowish orange, darker at base. Labium reddish brown. Sternum

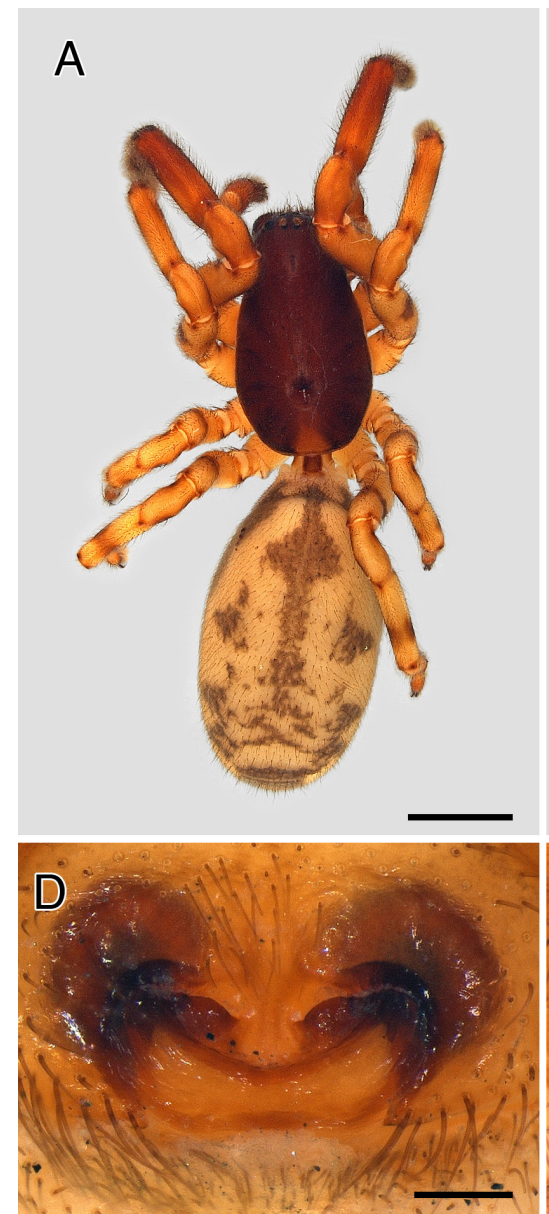

G

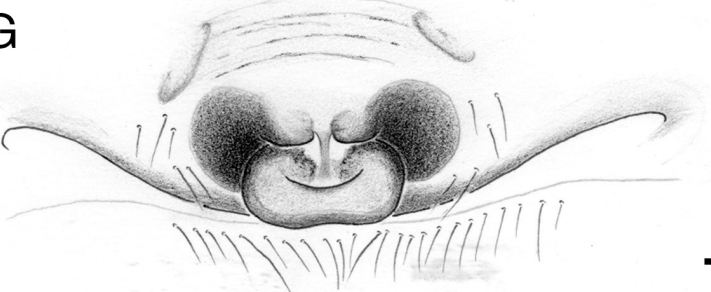

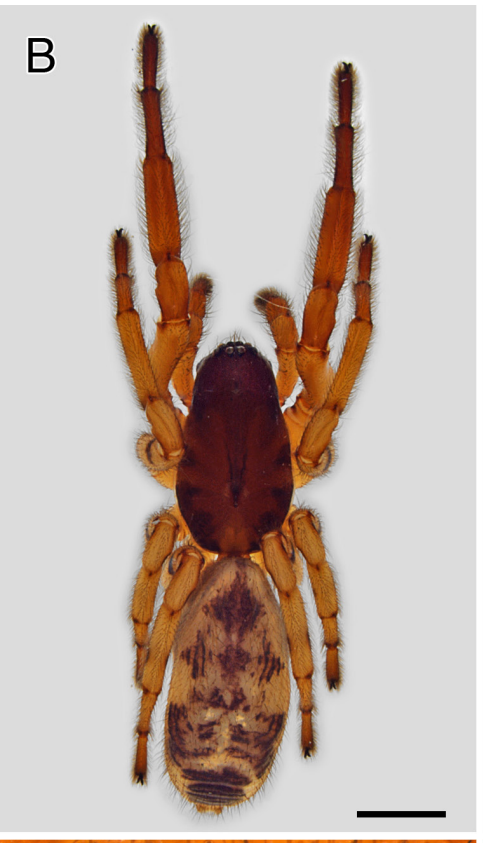

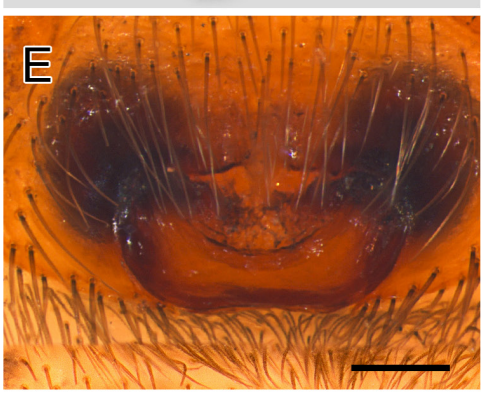

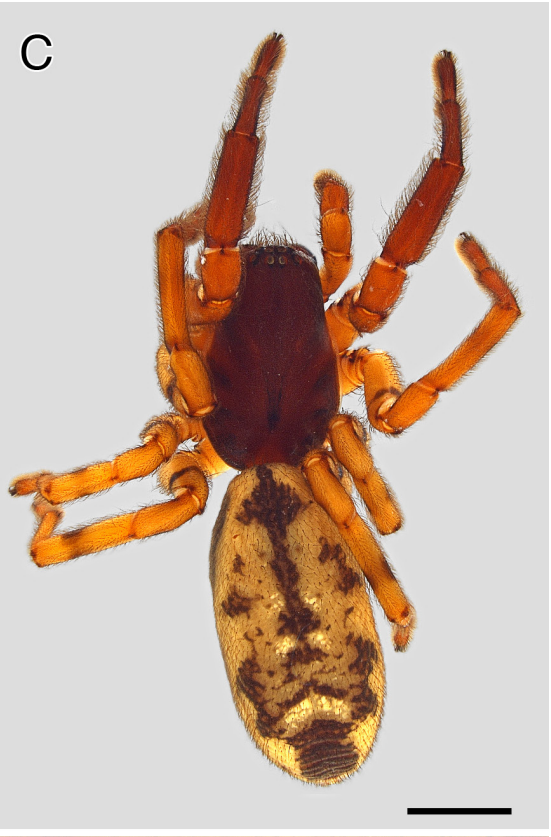

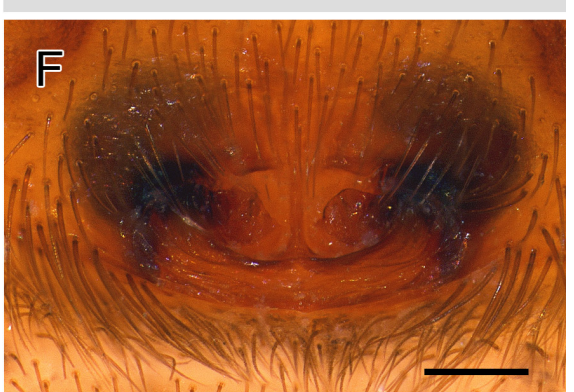

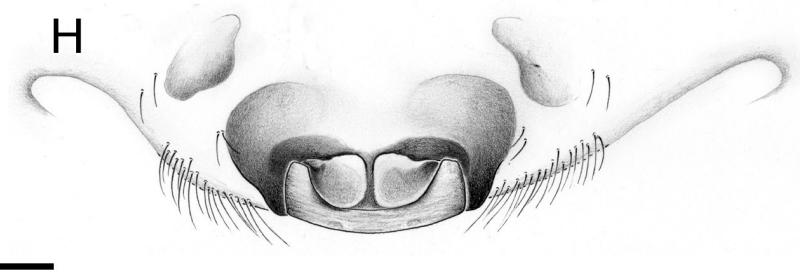

Fig. 7. Cicynethus decoratus (Lawrence, 1952) comb. nov. A, D. holotype,,+ . B, E, G. Female specimen (NCA2014/3298). C, F, H. Female specimen (RMCA_ARA_131806). A-C. Habitus, dorsal view. D-H. Epigyne, ventral view. Scale bars: A-C $=2 \mathrm{~mm}$; D-H $=0.2 \mathrm{~mm}$. 
medium brown, darkened along margin and with faint dark spots in posterior half; legs yellowish orange, darkened to medium brown on M tI, t I and t II, and extremity of t III and t IV; F and T II-IV with median ring on ventral half. Abdomen cream, dorsum with complex sepia dorsal pattern: diamond-shaped and 3 -segmented black spot in front of spinnerets; sides with one large frontal spot and two small posterior ones; venter with two longitudinal dark lines.

Sternum (Fig. 8C). Elongated oval, 1.14 wide, 1.63 long. Precoxal sclerites in front of coxae II.

Chilum. Two poorly defined triangles, each 0.07 high, 0.18 wide.

Eyes. ALE 0.15; AME 0.16; PLE 0.18; PME 0.15; ALE-AME 0.05; AME-AME 0.03; PLE-PME 0.12; PME-PME 0.08. Clypeus 0.30 high.
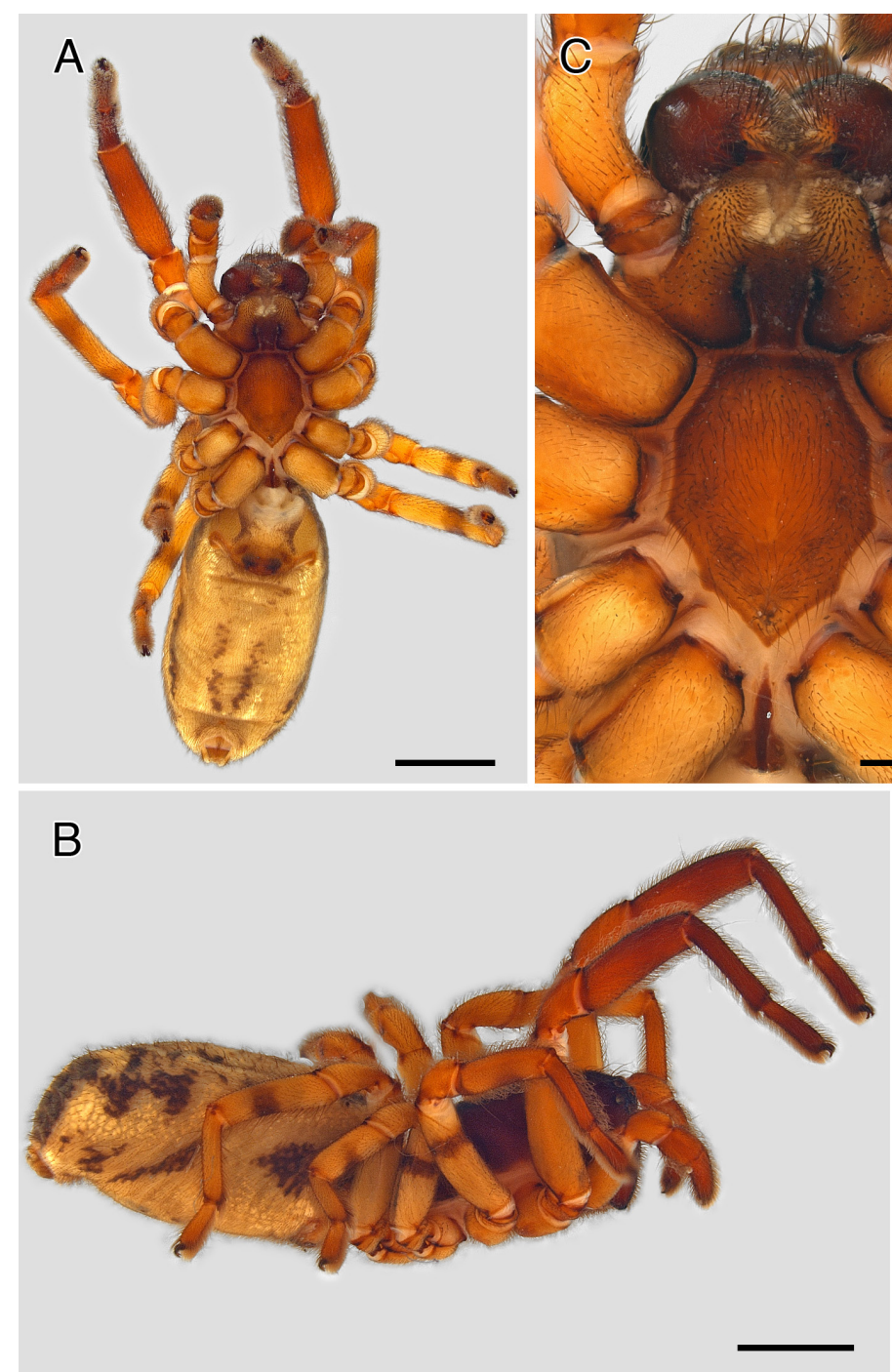
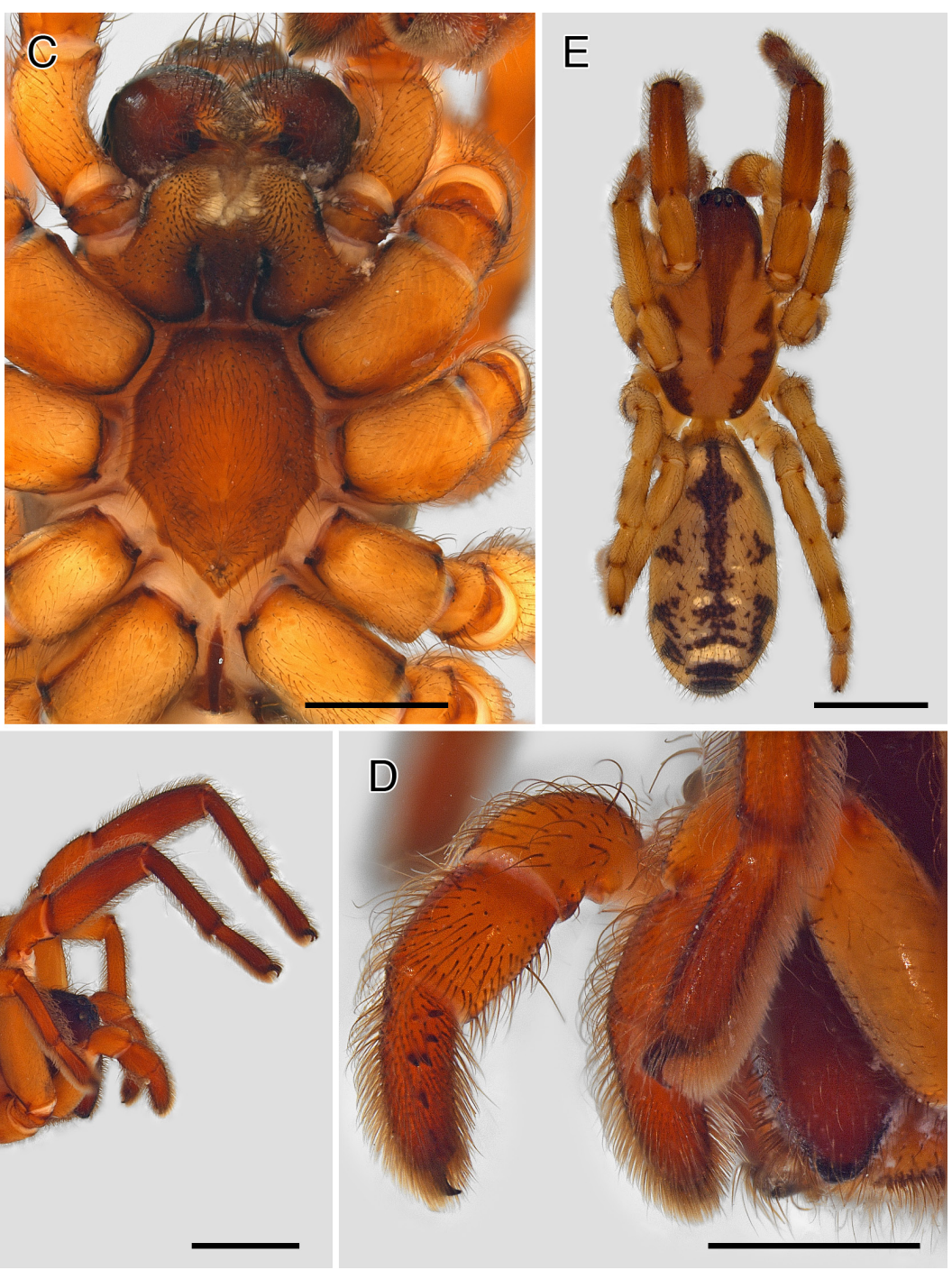

Fig. 8. Cicynethus decoratus (Lawrence, 1952) comb. nov. A-D. $q$ (RMCA_ARA_131806). E. Subadult $\delta$ (same sample). A. Habitus, ventral view. B. As preceding, lateral view. C. Prosoma, ventral view. D. Female palp, prolateral view. E. Habitus, dorsal view. Scale bars: A-B, E $=2 \mathrm{~mm} ; \mathrm{C}-\mathrm{D}=1 \mathrm{~mm}$. 
LEG MEASUREMENTS.

\begin{tabular}{ccccccc}
\hline & $\mathbf{F e}$ & $\mathbf{P}$ & $\mathbf{T i}$ & $\mathbf{M t}$ & $\mathbf{t}$ & Total \\
\hline I & 2.24 & 1.12 & 2.10 & 1.61 & 1.19 & 8.26 \\
II & 1.89 & 1.12 & 1.75 & 1.33 & 0.98 & 7.07 \\
III & 1.54 & 0.91 & 0.91 & 0.77 & 0.70 & 4.83 \\
IV & 2.03 & 1.12 & 1.61 & 1.19 & 0.77 & 6.72 \\
\hline
\end{tabular}

Legs. All Mt with four distal ventral spines in a series 1-2-1 with central ones closely set behind each other.

EPIGYNE (Fig. 7E). With broad plate, longer in front; with deep median indentation; produced into median septum; frontal corners of plate surrounded by dark circular area.

\section{Male}

Unknown. Subadult male (Fig. 8E) with contrasted pattern on carapace and abdomen.

\section{Distribution}

Known from the vicinity of Port Edward (Fig. 21).

\section{Variation}

Total length: 9.23-12.57. Carapace: length 4.12-5.11, width 2.34-2.91. The lateral dark triangles on the carapace may be very vague (Fig. 7C). The median septum in the epigyne is sometimes strongly developed, as in the female from Ingogo Forest (RMCA_ARA_131806) (Fig. 7F, H). Juveniles (n = 16, including subadult males and females from RMCA_ARA_131806) have a yellow carapace with a medium brown pattern consisting of a median band widening from the fovea towards the front, including the eye region and margins with a row of dark coalescing triangular spots (Fig. 8E); sternum with broad dark margins; legs and abdomen as in the adult female.

\section{Cicynethus floriumfontis Jocqué, 1991}

Figs 2A-C, 9-11, 21

Cicynethus floriumfontis Jocqué, 1991: 104, figs 236-241 (descr. ${ }_{\text {đ). }}^{\text {) }}$

\section{Diagnosis}

Both male and female of Cicynethus floriumfontis are recognized by the colour pattern, with numerous small dark spots and the broad dark bands on the carapace, the central one not reaching the PME.

\section{Material examined}

Holotype

SOUTH AFRICA: ${ }^{\wedge}$, Eastern Cape Province, Cradock, $32^{\circ} 19^{\prime}$ S, $25^{\circ} 39^{\prime}$ E, Aug-Oct. 1985, pitfall trap, museum staff leg. (NMBA 1170).

\section{Other material}

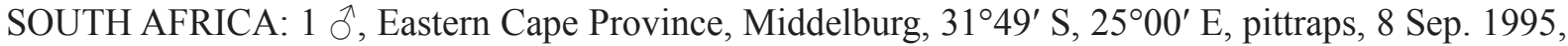
M. de Jager leg. (NCA 95/394); 1 ${ }^{\lambda}$, same collection data as for preceding but 3 Sep. 1995 (NCA 95/358); 1 ㅇ, same collection data as for preceding but 15 Mar. 1995 (NCA 95//243); 2 $\widehat{\partial}$, associated with termites, same collection data as for preceding but 8 May 1991(NCA 91/1051). 


\section{Description}

Male (NCA 95/394)

MeAsuremENTs. Total length: 11.50. Carapace: length 5.54, width 3.27, height 1.28.

Colour (Fig. 9A-C). Carapace brownish yellow with many tiny dark dots, brown median band widening towards the front, not reaching eye region; broad dark marginal bands with irregularly serrated median margin; chelicerae medium brown with darker condyle and dark spot near fang insertion and pale mediodistal spot; endites yellow; labium medium brown; sternum with yellow centre, darker margins

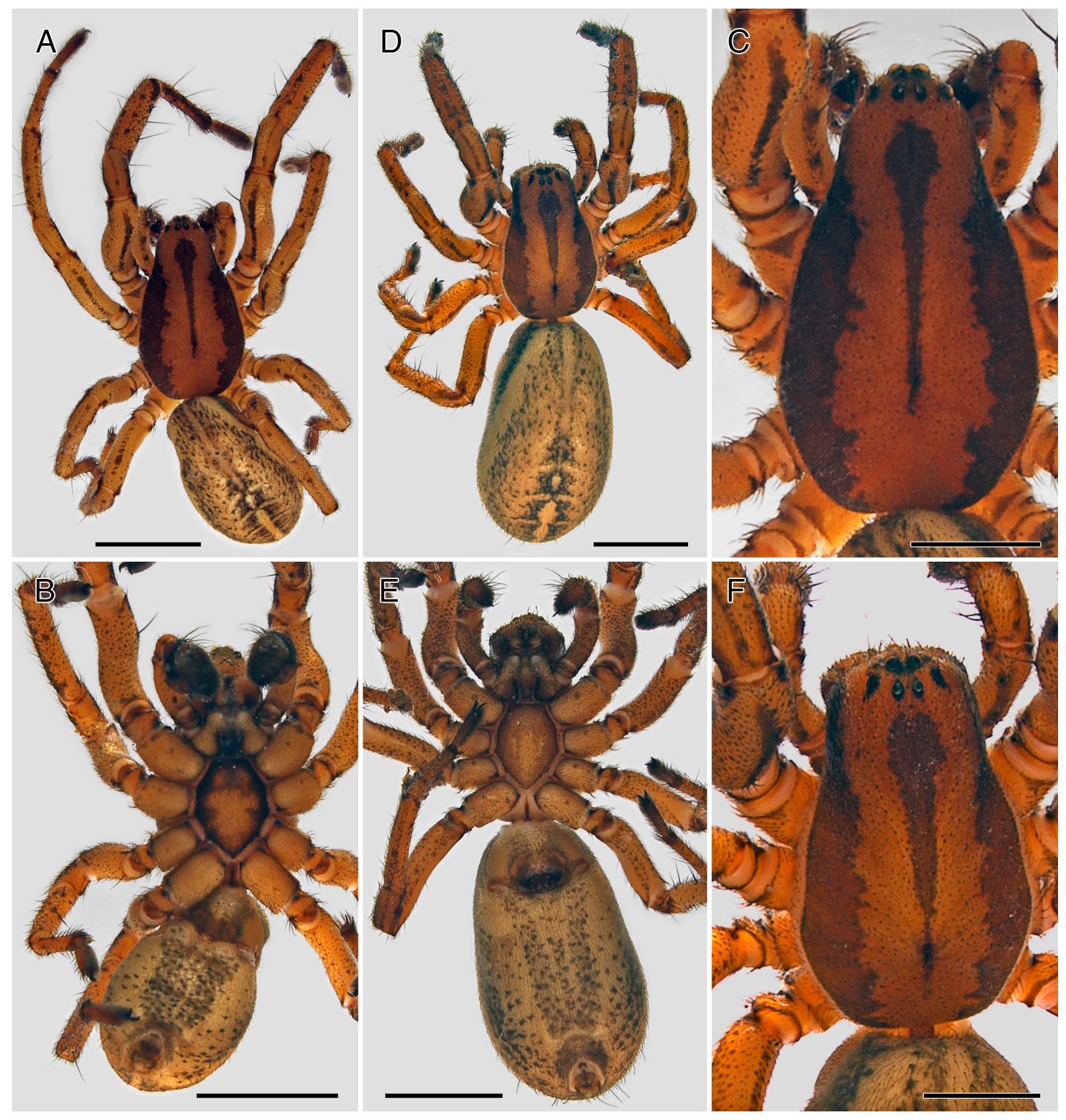

Fig. 9. Cicynethus floriumfontis Jocqué, 1991. A-C. $ð$ (NCA 95/385). D-F. $q$ (NCA 95/243). A. Habitus, dorsal view. B. As preceding, ventral view. C. Carapace, dorsal view. D. Habitus, dorsal view. E. As preceding, ventral view. F. Carapace, dorsal view. Scale bars: A-B, D-E $=2 \mathrm{~mm} ; \mathrm{C}, \mathrm{F}=1 \mathrm{~mm}$. 
and medium brown anterior part (Fig. 9B); legs brownish yellow with many dark spots at setae sockets; spots on F coalescing into dark dorsal median stripe (Fig. 9A); all P, T I and II, Mt I with dark proand retrolateral stripes; distal dorsal margin of trochanters and coxae brown; abdomen cream, sparsely dotted with small darker spots; epiandrum orange; spinnerets yellow (Fig. 9A-B).

Sternum (Fig. 9B). Elongated oval, 1.63 wide, 2.20 long. No precoxal sclerites.

ChILum. Two poorly defined triangles, each 0.11 high, 0.23 wide.
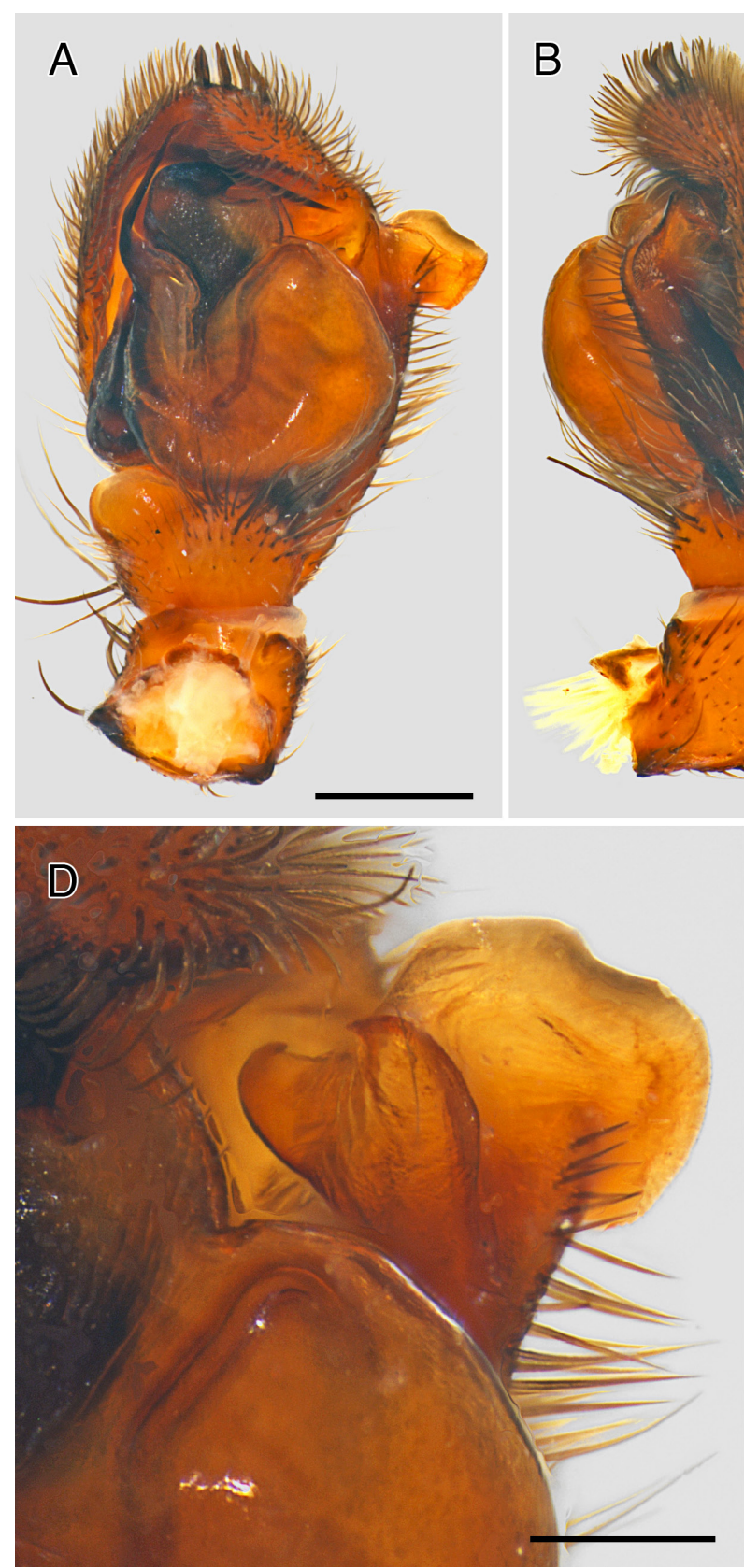
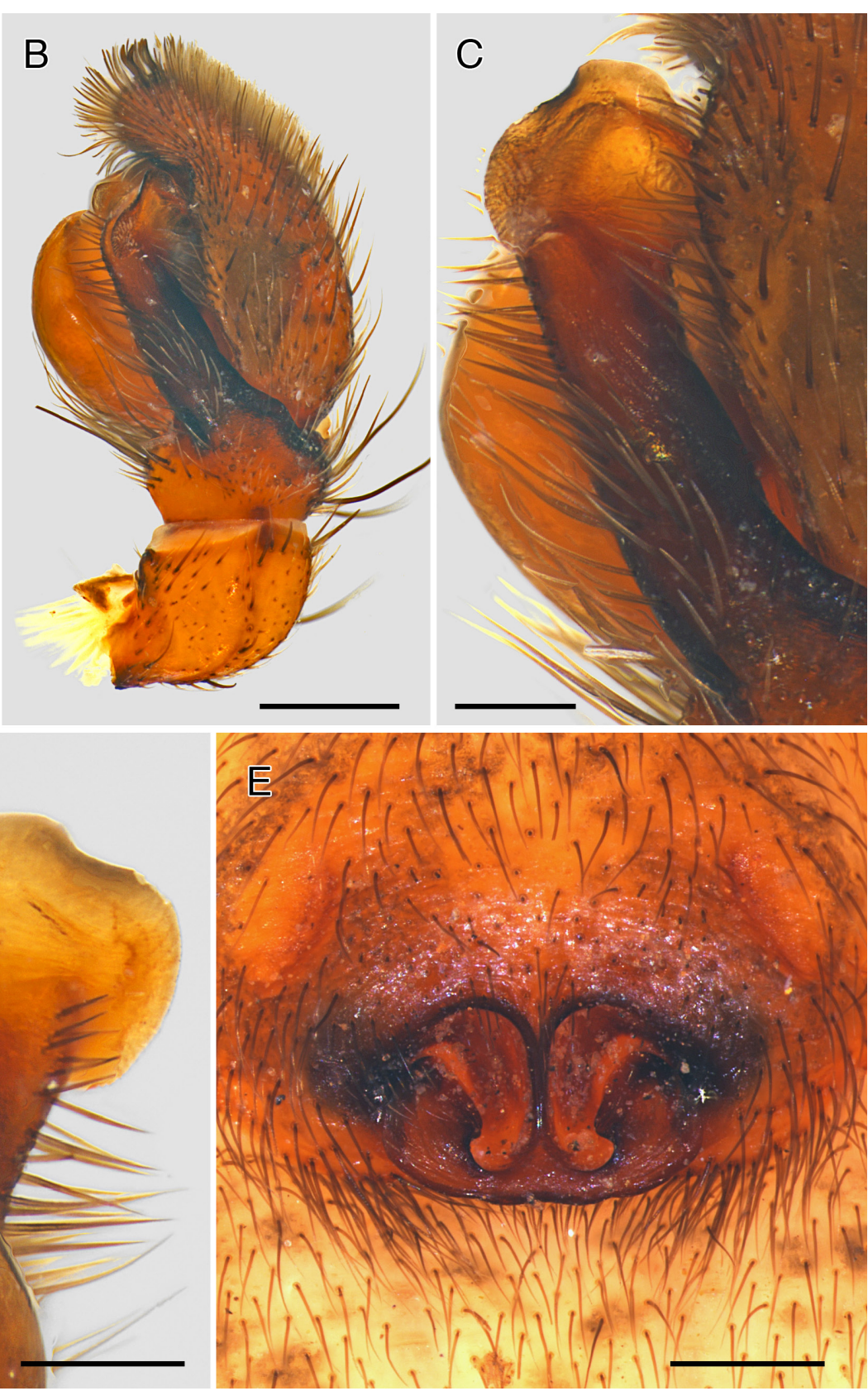

Fig. 10. Cicynethus floriumfontis Jocqué, 1991. A-D. ¿̊ (NCA 95/385). E. + (NCA 95/243). A. Male palp, ventral view. B. As preceding, retrolateral view. C. Detail of RTA, retrolateral view. D. Distal tip of RTA, ventral view, slightly oblique. E. Epigyne, ventral view. Scale bars: A-B, E $=0.2 \mathrm{~mm}$; C-D = $0.1 \mathrm{~mm}$. 
Eyes. ALE 0.18; AME 0.23; PLE 0.18; PME 0.16; ALE-AME 0.08; AME-AME 0.08; PLE-PME 0.25; PME-PME 0.10. Clypeus 0.36 high.

LEG MEASUREMENTS.

\begin{tabular}{ccccccc}
\hline & Fe & P & Ti & Mt & t & Total \\
\hline I & 3.85 & 1.75 & 3.36 & 2.80 & 1.47 & 13.23 \\
II & 3.29 & 1.75 & 2.87 & 2.31 & 1.26 & 11.48 \\
III & 2.73 & 1.40 & 1.82 & 1.68 & 1.19 & 8.82 \\
IV & 3.71 & 1.47 & 2.73 & 2.52 & 1.33 & 11.76 \\
\hline
\end{tabular}

LEGS. With numerous long, hinged hairs. Spination: All Mt with four distal ventral spines in a series d1 sd2-1 with central ones closely set behind each other.

Male palp (Figs 10A-D, 11A-B). RTA large, broad, dorsal margin at base with shallow triangular extension; distal extremity complex, with two flat ledges, one transverse, broad, turned upwards, one longitudinal, much smaller, with rounded extremity; cymbium with two distal curved spines and one prolateral spine; tegulum strongly swollen, with sperm duct sinuous, narrow, distal part entering embolus invisible; embolus membranous at base, slightly curved; MA almost straight, pointing out and backwards.

\section{Female (NCA 95//243)}

MeAsurements. Total length: 13.49. Carapace: length 5.68, width 3.20, height 1.49.

CoLour (Fig. 9D-F). Very similar to male except sternum almost entirely yellowish brown with narrow darker margin (Fig. 9E).

Sternum (Fig. 9E). Elongated oval, 1.78 wide, 2.34 long. Precoxal sclerites at coxae II.

Chilum. Two poorly defined triangles, each 0.10 high, 0.26 wide.

Eyes. ALE 0.12; AME 0.18; PLE 0.15; PME 0.13; ALE-AME 0.10; AME-AME 0.13; PLE-PME 0.28; PME-PME 0.15. Clypeus 0.49 high.

LEG MEASUREMENTS.

\begin{tabular}{ccccccc}
\hline & Fe & P & Ti & Mt & t & Total \\
\hline I & 3.71 & 1.89 & 3.08 & 2.24 & 1.40 & 12.32 \\
II & 3.08 & 1.54 & 2.59 & 2.03 & 1.33 & 10.57 \\
III & 2.52 & 1.54 & 1.68 & 1.19 & 1.05 & 7.98 \\
IV & 3.22 & 1.54 & 2.45 & 1.96 & 1.26 & 10.43 \\
\hline
\end{tabular}

LEGS. With numerous long, hinged hairs. Spination: as in male.

Epigyne (Figs 10E, 11C). Atria large, strongly curved, separated by well-developed, narrow median septum ending anteriorly in two arches.

\section{Variation}

The colour pattern of the males, mainly that of the legs and the spots on the abdomen, may vary in intensity. The number of distal cymbial spines varies between two and five. 


\section{Distribution}

Known from two localities in the Eastern Cape Province, South Africa (Fig. 21).

\section{Natural history}

No details are known on the habitat in which the specimens were collected. One specimen was 'caught in association with termites' without further explanation.

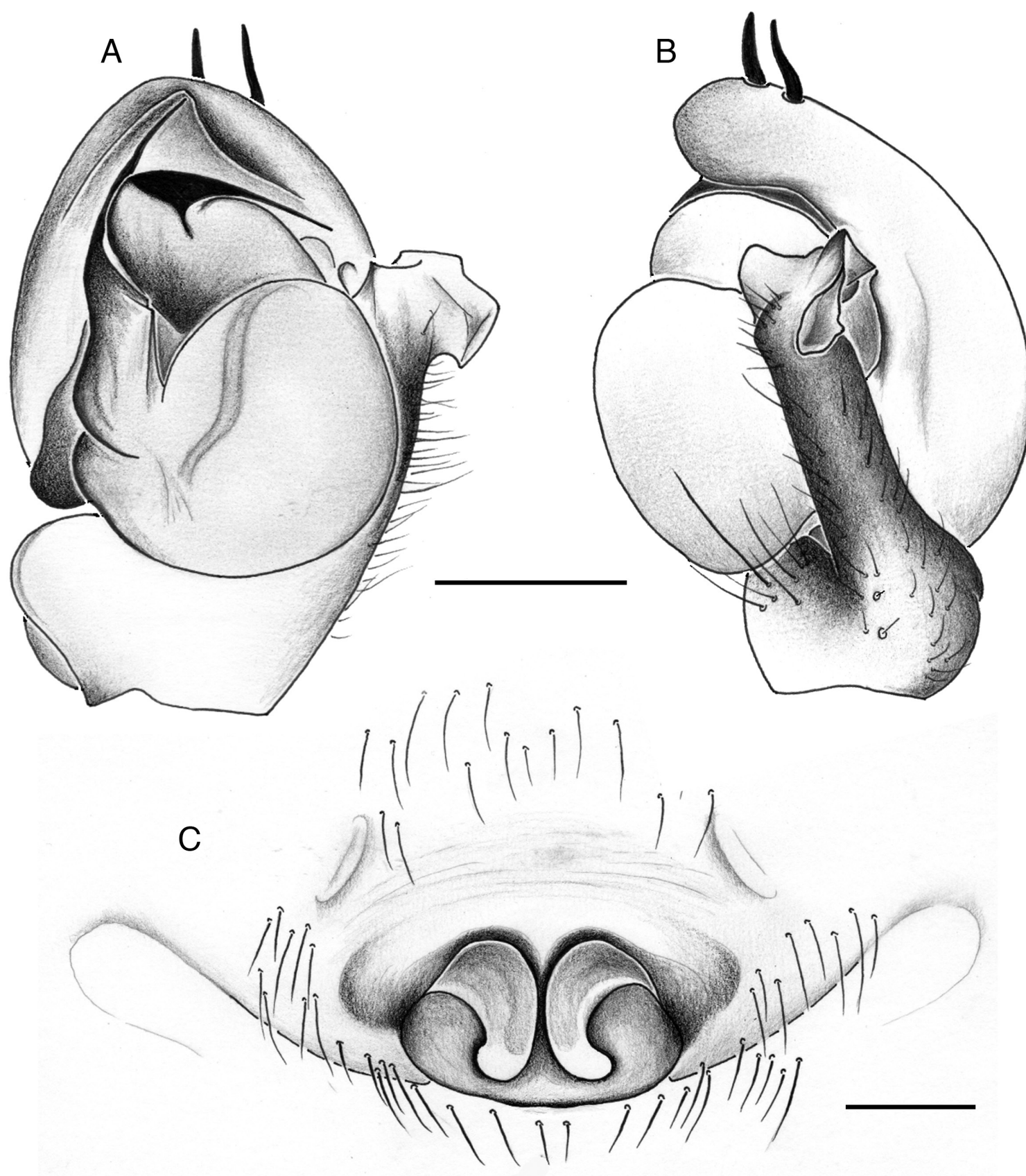

Fig. 11. Cicynethus floriumfontis Jocqué, 1991, genitalia drawings. A-B. $\widehat{\partial}$ (NCA 95/394). C. $q$ (NCA 95/243). A. Male palp, ventral view. B. As preceding, retrolateral view. C. Epigyne, ventral view. Scale bars: $0.2 \mathrm{~mm}$. 
Cicynethus mossambicus sp. nov. urn:1sid:zoobank.org:act:EF8D0370-1C32-4EB9-91DD-97BD0367EBF7

Figs 2D-E, 12-14, 22

\section{Diagnosis}

Both male and female Cicynethus mossambicus sp. nov. are recognized by the uniform dark chestnut carapace and the hairy legs; males are recognized by the shape of the RTA, the simple, not strongly swollen tegulum and the distal tegular protrusion (DTP); females by the epigyne provided with broad procurved scape and the wide but short median septum separating the small copulatory openings.

\section{Etymology}

The species name is an adjective referring to the country where it is found.

\section{Material examined}

\section{Holotype}

MOZAMBIQUE: ${ }^{\lambda}$, Niassa region, Sanga Plateau, $12^{\circ} 24^{\prime} 00.7^{\prime \prime}$ S, $35^{\circ} 20^{\prime} 07.0^{\prime \prime}$ E, montane forest, pitfall with fence, 15 Nov. 2016, L. Geeraert and M. Jocqué leg. (RMCA_ARA_245528).

\section{Paratypes}

MOZAMBIQUE: 1 q, Niassa region, Njesi Plateau, 12 ${ }^{\circ} 49^{\prime} 53.3^{\prime \prime} \mathrm{S}, 35^{\circ} 11^{\prime} 10.0^{\prime \prime} \mathrm{E}$, montane forest,

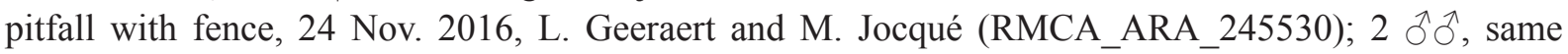
locality as for holotype, Malaise trap, 18 Nov. 2016, L. Geeraert and M. Jocqué (RMCA_ARA_245538).

\section{Description}

\section{Holotype (male)}

MEASUREMENTS. Total length: 10.79. Carapace: length 4.76, width 2.77, height 1.14.

Colour (Fig. 12A-B). Carapace dark chestnut brown with small pale brown patch at posterior margin. Chelicerae dark brown; endites brown, with distal half white; labium brown, with distal margin white; legs: tarsi brown with pale ring at base; metatarsi dark brown; tibia I with broad dark ring at base and distal extremity, orange in between, tibia II similar to I but orange part longer; tibiae III and IV: yellow with dark rings at base and distal extremity; trochanters orange with brown parts; coxae dark brown, with large ventral yellow patch; abdomen cream with dark median stripe ending in two triangles followed by interrupted chevrons; sides cream with longitudinal stripe all along; venter pale, with two faint longitudinal stripes; spinnerets greyish brown.

Sternum. Elongated oval, with sinuous lateral margins, 1.42 wide, 2.13 long.

ChiLum. Two poorly defined triangles, each 0.07 high, 0.25 wide.

Eyes. ALE 0.15; AME 0.18; PLE 0.18; PME 0.16; ALE-AME 0.03; AME-AME 0.07; PLE-PME 0.13; PME-PME 0.08. Clypeus 0.12 high.

LEG MEASUREMENTS.

\begin{tabular}{ccccccc}
\hline & Fe & P & Ti & Mt & t & Total \\
\hline I & 3.01 & 1.47 & 2.66 & 2.59 & 1.61 & 11.34 \\
II & 2.52 & 1.33 & 2.87 & 2.03 & 1.47 & 10.22 \\
III & 2.03 & 1.12 & 1.75 & 1.40 & 1.12 & 7.42 \\
IV & 2.52 & 1.26 & 2.73 & 2.03 & 1.26 & 9.80 \\
\hline
\end{tabular}


Legs. T and Mt covered with long hairs. Spination: with distal ventral spines Mt I: d3; Mt II: d2 sd1; Mt III: d3 sd1; Mt IV: d3 sd1; spines almost as long as diameter of segment.

MALE PALP (Figs 2D-E, 13A-C, 14A-B). RTA a long rectangular prong, distal end tapered to rounded tip; knob ventral of RTA base; tegulum not strongly swollen, with distal tegular protrusion (DTP); embolus thin, slightly curved, originating in centre on prolateral side of tegulum, directed forward; MA directed retrolaterad, thin, straight, with sharp tip; posterior part of tegulum bulging backward.

Paratype (female, RMCA_ARA_245530)

MEASUREMENTS. Total length: 13.14. Carapace: length 5.75, width 2.48, height 1.07.

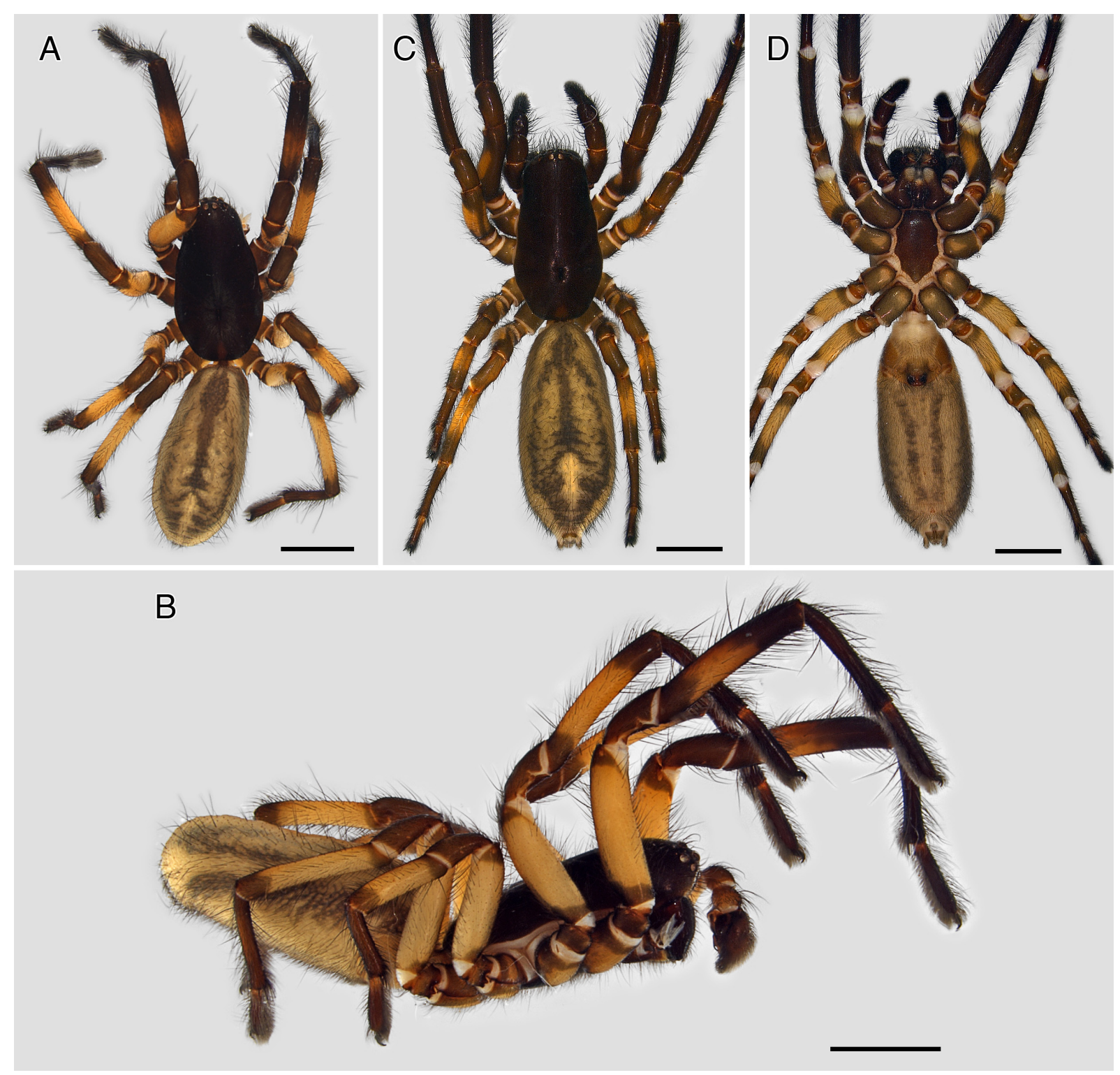

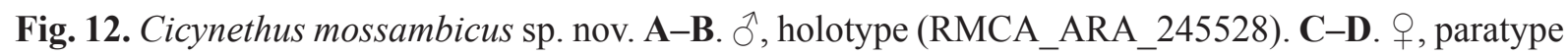
(RMCA_ARA_245530). A. Habitus, dorsal view. B. As preceding, lateral view. C. Habitus, dorsal view. D. As preceding, ventral view. Scale bars: $2 \mathrm{~mm}$. 
Colour (Fig. 12C-D). Carapace, chelicerae sternum and abdomen as in male. Legs less contrasted: entirely medium brown except femora yellow with dark rings at base and distal extremity and dark dorsal stripe, broadest on Fe I.

Sternum (Fig. 12D). Elongated oval with sinuous lateral margins, 1.42 wide, 2.13 long.

ChILUM. Two poorly defined triangles, each 0.07 high, 0.25 wide.

Eyes. ALE 0.18; AME 0.16; PLE 0.16; PME 0.21; ALE-AME 0.02; AME-AME 0.12; PLE-PME 0.08; PME-PME 0.13. Clypeus 0.10 high.

LEG MEASUREMENTS.

\begin{tabular}{ccccccc}
\hline & Fe & P & Ti & Mt & t & Total \\
\hline I & 2.94 & 1.75 & 3.15 & 2.45 & 1.96 & 12.25 \\
II & 2.80 & 1.54 & 2.87 & 1.96 & 1.75 & 10.92 \\
III & 2.45 & 1.33 & 1.75 & 1.33 & 0.98 & 7.84 \\
IV & 3.08 & 1.47 & 2.59 & 1.89 & 1.12 & 10.15 \\
\hline
\end{tabular}
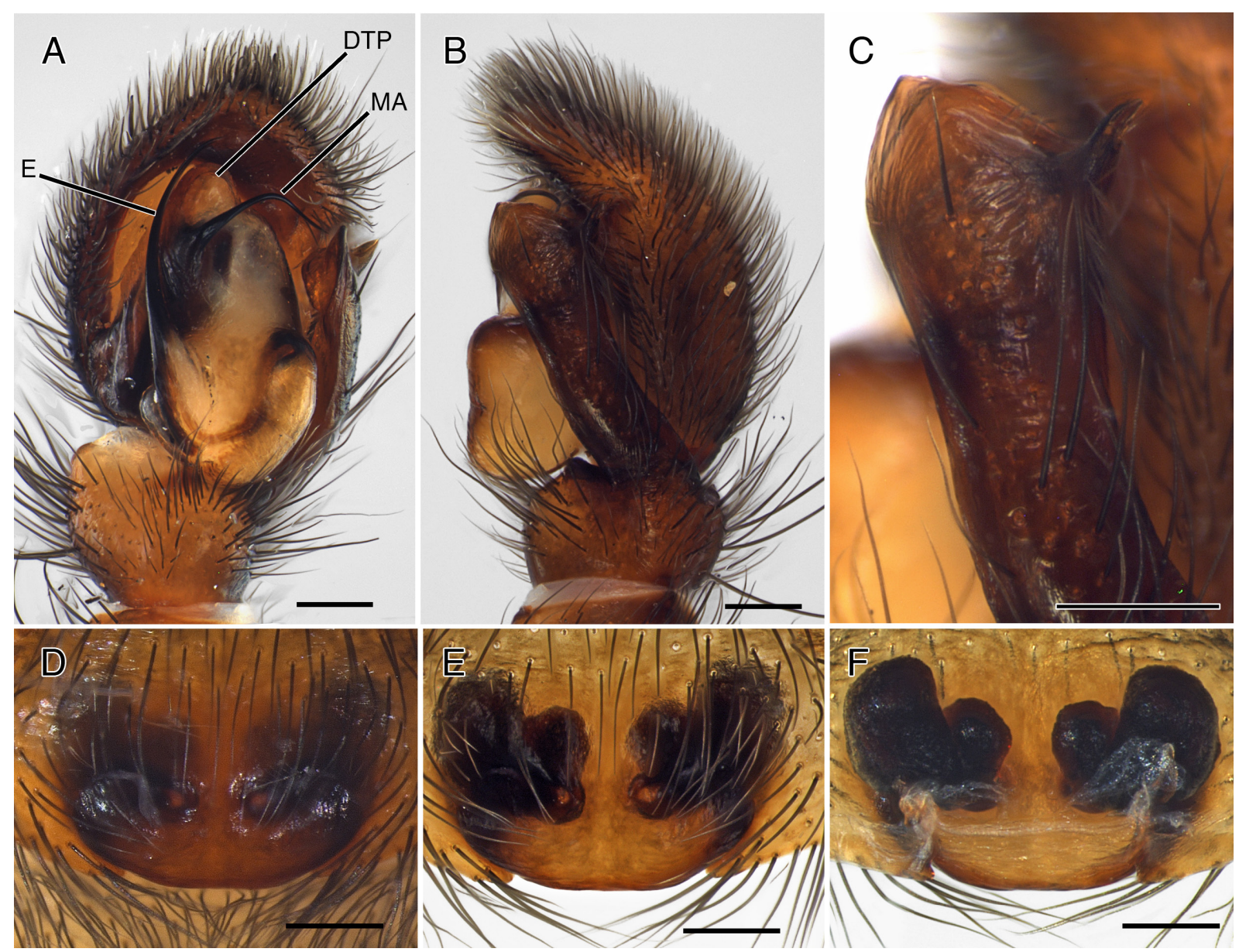

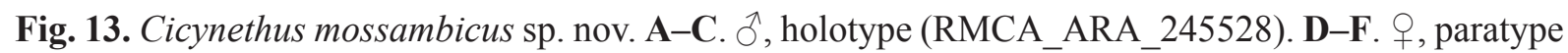
(RMCA_ARA_245530). A. Male palp, ventral view. B. As preceding, retrolateral view. C. Distal tip of RTA, retrolateral view. D. Epigyne, ventral view. E. Epigyne, digested, ventral view. F. As preceding, dorsal view. Abbreviations: DTP = distal tegular protrusion; $\mathrm{E}=$ embolus; $\mathrm{MA}=$ median apophysis. Scale bars: $0.2 \mathrm{~mm}$. 
Legs. T and Mt covered with long hairs. Spination: with distal ventral spines Mt I: d1; Mt II: d2 sd1, subdistal; Mt III: d3 sd1+1; Mt IV: $\mathrm{d} 3 \mathrm{sd} 1+1$; spines almost as long as diameter of segment.

EpIGyNe (Figs 13D-F, 14C). Transverse oval sclerotized area with broad procurved scape, copulatory openings separated by thick but short median septum.

\section{Distribution}

Known from mountain area in northwest Mozambique (Fig. 22).
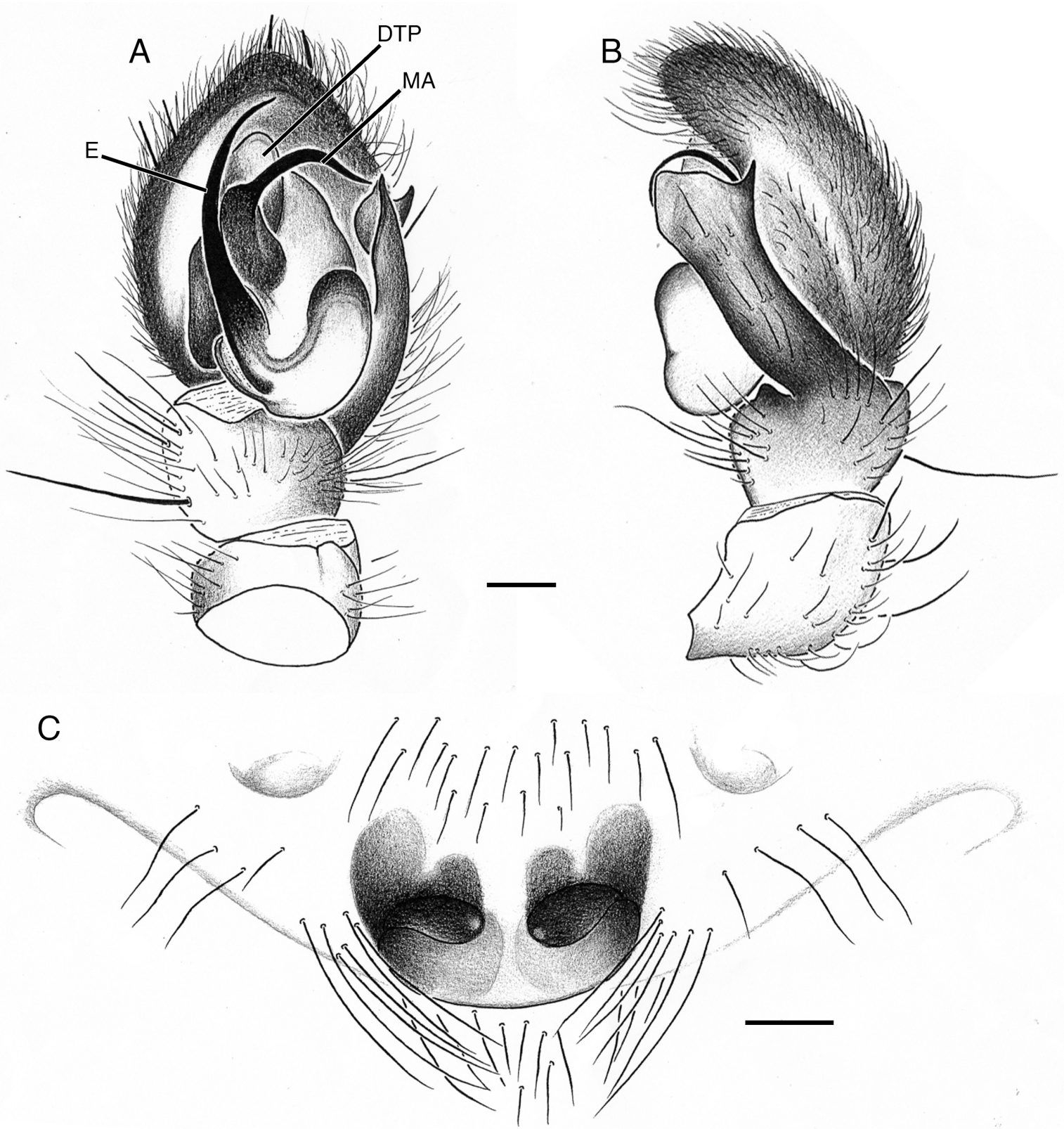

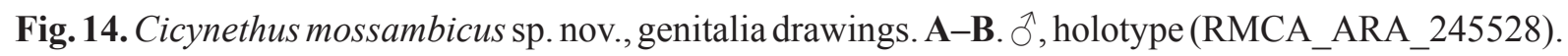
C. , paratype (RMCA_ARA_245530). A. Male palp, ventral view. B. As preceding, retrolateral view. C. Epigyne, ventral view. Abbreviations: DTP = distal tegular protrusion; $\mathrm{E}=$ embolus; $\mathrm{MA}=$ median apophysis. Scale bars: $0.2 \mathrm{~mm}$. 


\section{Natural history}

Specimens were found by sieving forest litter and in a Malaise trap, which indicates that they are moving between the litter layer and the shrub layer.

Cicynethus subtropicalis (Lawrence, 1952) comb. nov.

Figs $1 \mathrm{~A}-\mathrm{G}, 2 \mathrm{~F}-\mathrm{H}, 15-19,20 \mathrm{~A}-\mathrm{B}, 21$

Chariobas subtropicalis Lawrence, 1952: 195, fig. 25 (descr. ㅇ).

\section{Diagnosis}

Both male and female of Cicynethus subtropicalis comb. nov. are recognized by the colour pattern of the legs and abdomen; the male palp is similar to that of $C$. floriumfontis, with the strongly protruding tegulum in which the sperm duct is visible on the prolateral side, but is distinguished by the shape of the RTA, with two ledges perpendicular to each other; the female by the details of the abdomen, with large atria and faint median septum emerging from the anterior margin of the posterior plate.

\section{Material examined}

\section{Holotype}

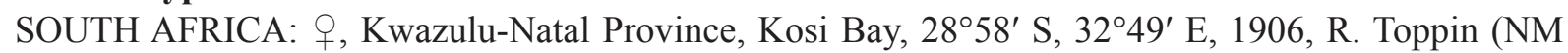
1161).

\section{Other material}

SOUTH AFRICA: Kwazulu-Natal Province: 1 d, Simangaliso Wetland Park, Mkhuze Game Reserve, 2738'42" S, 3209'30" E, pitfall trap, B13, 18 Jul. 2008, X. Combrink leg. (NCA 2016/842); 1 ô, Ndumo Game Reserve, 26 53'37" S, 32 $2^{\circ} 15^{\prime} 18^{\prime \prime}$ E, broadleaf woodland, sweepnet, 10 Feb. 2005, C. Haddad leg. (NCA 2008/4266); 1 त, deep sand forest, under tree bark, same collection data as for preceding but 11 Jan. 2007 (NCA 2007/3035); 1 ㅇ, Ndumo Game Reserve, 26 $6^{\circ} 58^{\prime} \mathrm{S}, 32^{\circ} 25^{\prime} \mathrm{E}$, on bush,

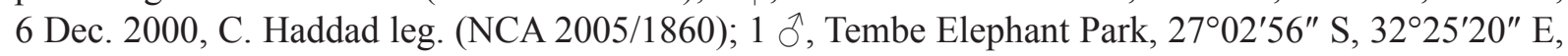
open woodland, searching shrub foliage, 9 Jan. 2009, C. Haddad leg. (NCA 2007/3203; drawings); 1 ; leaf litter, same collection data as for preceding but 21 Jan. 2002 (RMCA_ARA_211745; drawing; DNA extraction); 1 \&, 1 juv., sweep grass and herbs, same collection data as for preceding but 12 Jan. 2002 (NCA 2007/3556; drawing); 2 우, Empangeni, 28 $43^{\prime} \mathrm{S}, 31^{\circ} 52^{\prime} \mathrm{E}$, bush, marshy ground, 17 May 1975, P. Reavell leg. (NCA 2000/438).

\section{Description}

Holotype (female, NMSA 1161)

MeAsurements. Total length: 11.50. Carapace: length 4.97, width 2.70, height 1.42.

Colour (Fig. 15D). Carapace medium brown, reddish brown around fovea; chelicerae reddish brown, with distal antero-median pale patch; endites and labium pale yellow; sternum brownish yellow in front to pale yellow at the back; legs greyish yellow, stronger first pair reddish brown from P onwards; abdomen uniform grey with ill-defined darker median dorsal stripe ending in white longitudinal bar.

Sternum (Fig. 16A). Elongated oval, 1.49 wide, 2.13 long. Precoxal sclerites at coxae II-IV.

Eyes. ALE 0.15; AME 0.16; PLE 0.15; PME 0.13; ALE-AME 0.05; AME-AME 0.05; PLE-PME 0.16; PME-PME 0.10. Clypeus 0.33 high, with several long setae.

Chilum. Poorly defined, two sclerites each 0.36 wide, 0.10 high. 
Legs spination. Distal ventral spines Mt I: d3 sd1; Mt II: d3 sd1; Mt III: d2 sd1; Mt IV: d2 sd1-1.

EPIGYNe (Fig. 15A). With posterior, slightly procurved plate, in the middle produced into median septum, delimiting large atria; large dark area on either side.

\section{Note}

Since the holotype was collected more than 110 years ago, it is not surprising that is bleached. We therefore provide the description of a more recent female in addition to the description of a male.
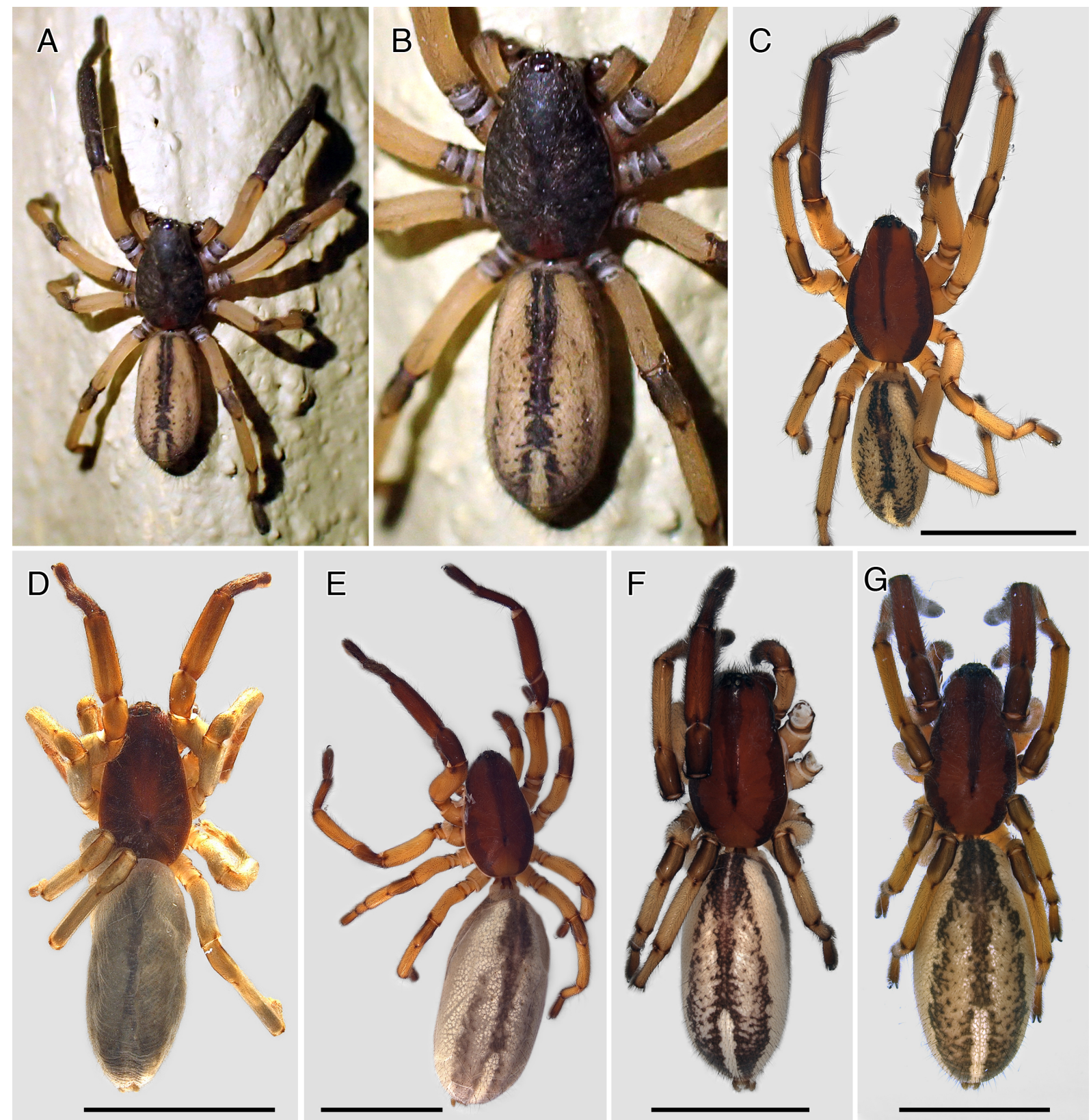

Fig. 15. Cicynethus subtropicalis (Lawrence, 1952) comb. nov., habitus, dorsal views. A-B. $\widehat{\partial}$, in vivo (Nambiti Game Reserve, Kwazulu Natal; courtesy of Bennie Kruger). C. § (NCA 2007/3035). D. ㅇ, holotype (NM 1161). E. + (NCA 2005/1820). F. + (RMCA_ARA_211745). G. + (NCA 2007/3556). Scale bars: $2 \mathrm{~mm}$. 


\section{Male (NCA 2016/842)}

MEASUREMENTS. Total length: 10.37. Carapace: length 4.97, width 2.91, height 0.78 .

CoLour (Fig. 15A). Carapace reddish brown with darker median band in front of fovea, widening towards the front, reaching eye region; dark marginal bands with irregularly serrated median margin; chelicerae reddish brown with distal median part white; endites yellowish orange; labium reddish brown; sternum reddish brown with darker margins in anterior half; legs: all $\mathrm{F}$ yellow with distal dorsal extremity dark brown, remainder of first leg pair reddish brown; second pair with $\mathrm{P}$ brown, $\mathrm{T}$ yellow, Mt and t brown; third and fourth pairs with P yellow with brown sides, remainder yellow to slightly orange on Mt and $\mathrm{t}$; abdomen base colour cream; dorsum with three dark stripes, the median one divided by thin white line anteriorly and by large white bar in posterior third; venter with white mottling; spinnerets yellow.

Sternum. Elongated oval, 1.56 wide, 2.13 long. Precoxal sclerites absent.

ChILum. Poorly defined, two sclerites each 0.08 high, 0.30 wide.

Eyes. ALE 0.20; AME 0.16; PLE 0.20; PME 0.16; ALE-AME 0.07; AME-AME 0.07; PLE-PME 0.16; PME-PME 0.10. Clypeus 0.33 high, with several long setae.

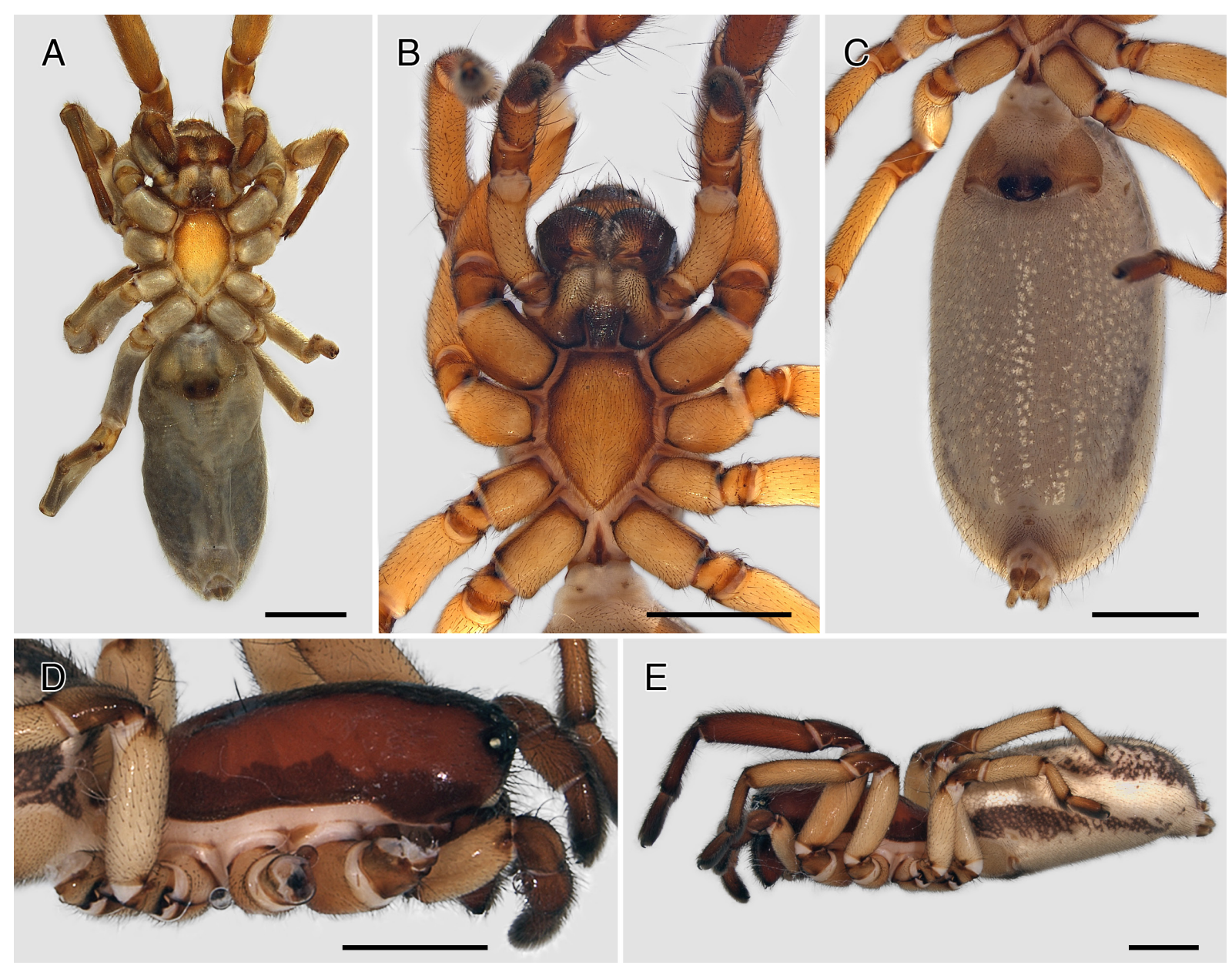

Fig. 16. Cicynethus subtropicalis (Lawrence, 1952) comb. nov. A. ㅇ, holotype (NM 1161). B-C. + (NCA 2005/1860). D-E. + (RMCA_ARA_211745). A. Habitus, ventral view. B. Prosoma, ventral view. C. Abdomen, ventral view. D. Prosoma, lateral view. E. Habitus, lateral view. Scale bars: 2 mm. 
LEG MEASUREMENTS.

\begin{tabular}{ccccccc}
\hline & $\mathbf{F e}$ & $\mathbf{P}$ & $\mathbf{T i}$ & $\mathbf{M t}$ & $\mathbf{t}$ & Total \\
\hline I & 3.15 & 1.68 & 3.36 & 2.45 & 1.47 & 12.11 \\
II & 2.66 & 1.40 & 2.80 & 1.82 & 1.26 & 9.94 \\
III & 2.17 & 1.19 & 1.54 & 1.33 & 0.91 & 7.14 \\
IV & 2.94 & 1.40 & 2.45 & 1.96 & 1.19 & 9.94 \\
\hline
\end{tabular}

Legs. With numerous long, hinged hairs. All Mt with four distal ventral spines in a series $1-2-1$ with central ones closely set behind each other.

Male Palp (Figs 18A-I, 19A-D). RTA large, tapered to extremity with two ledges, one transverse, rounded, the other one perpendicular to that, bluntly pointed; cymbium short, with two distal spines; tegulum strongly protruding, sperm duct on prolateral side narrowed before entering strongly curved embolus; MA slightly curved, pointing outward.

Female (NCA 2005/1860)

MeAsuREMENTs. Total length: 14.41. Carapace: length 5.98, width 3.20, height 1.42.
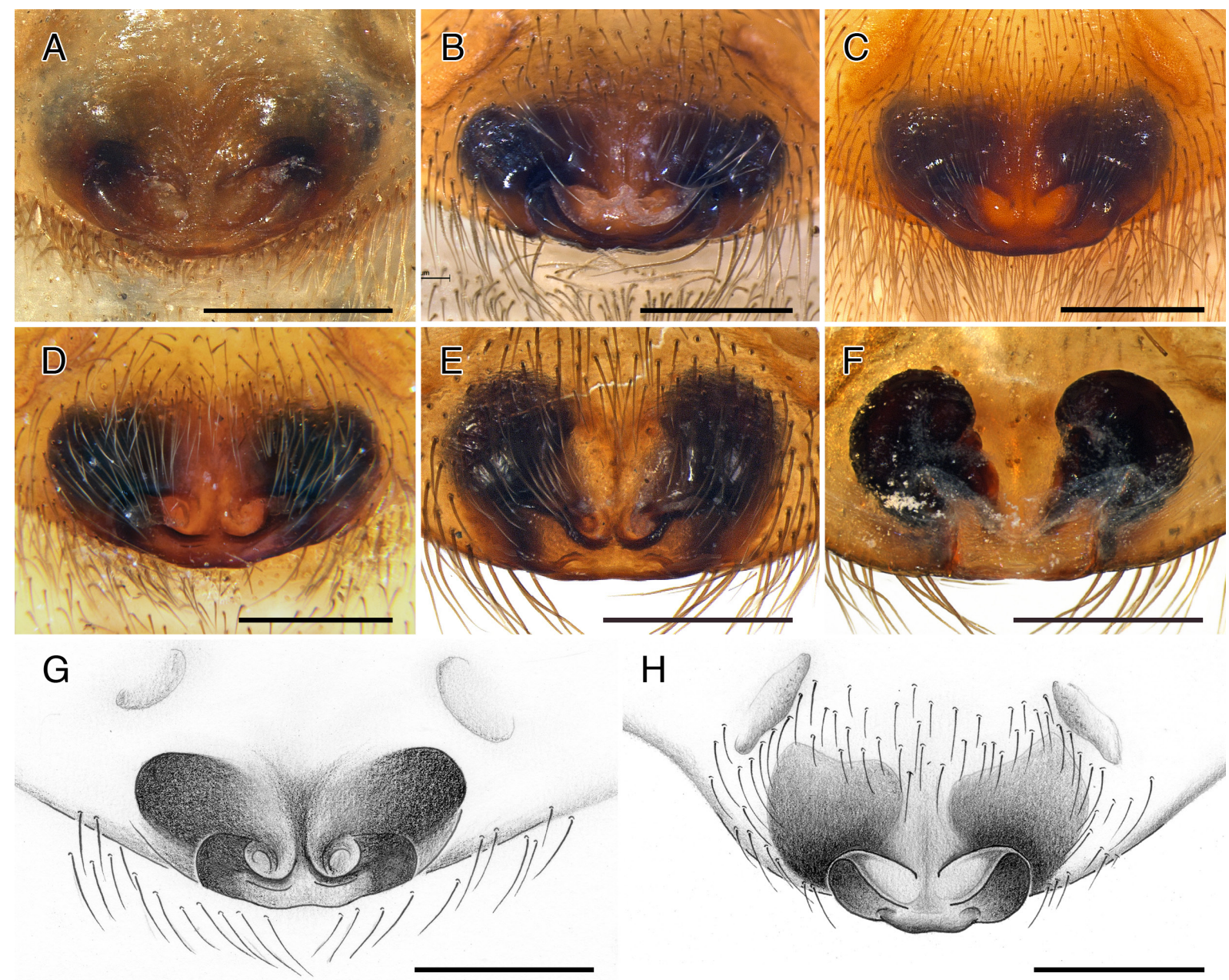

Fig. 17. Cicynethus subtropicalis (Lawrence, 1952) comb. nov., , epigynes. A. Holotype (NM 1161). B. NCA 2005/1860. C, H. RMCA_ARA_211745. D, G. NCA 2007/3556. E-F. NCA 2000/438. A-E, $\mathrm{G}-\mathrm{H}=$ ventral views; $\mathrm{F}=$ dorsal view. Scale bars: $0.5 \mathrm{~mm}$. 

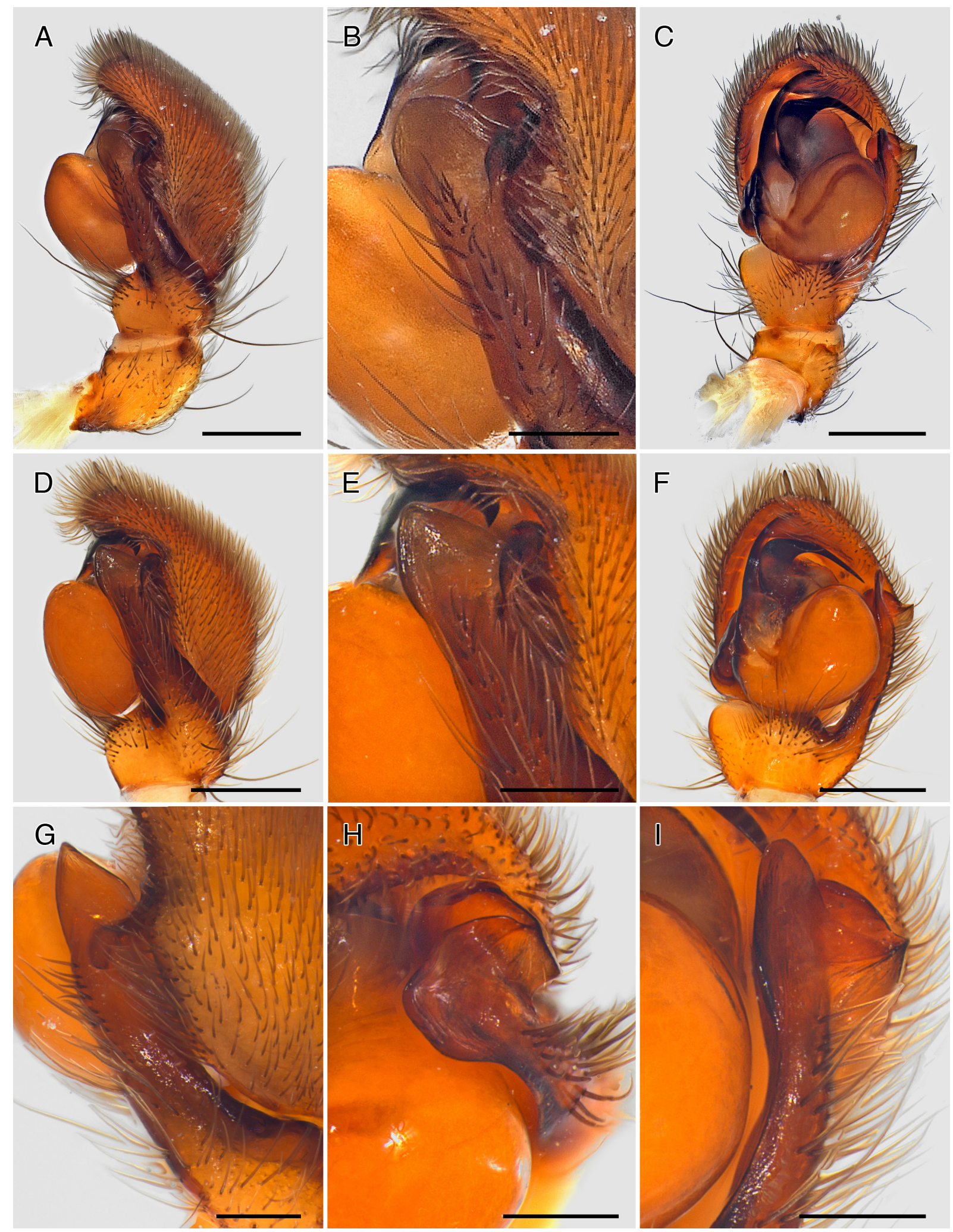

Fig. 18. Cicynethus subtropicalis (Lawrence, 1952) comb. nov., male palps. A-C. NCA 2007/3035. D-I. NCA 2016/842. A, D. Retrolateral views. B, E. Apex of RTA, retrolateral views. C, F. Ventral views. G. RTA, dorsal, slightly lateral view. H. Apex of RTA, frontal view. I. As preceding, ventral view. Scale bars: A, C-D, F $=0.5 \mathrm{~mm}$; B, E, G-I $=0.2 \mathrm{~mm}$. 

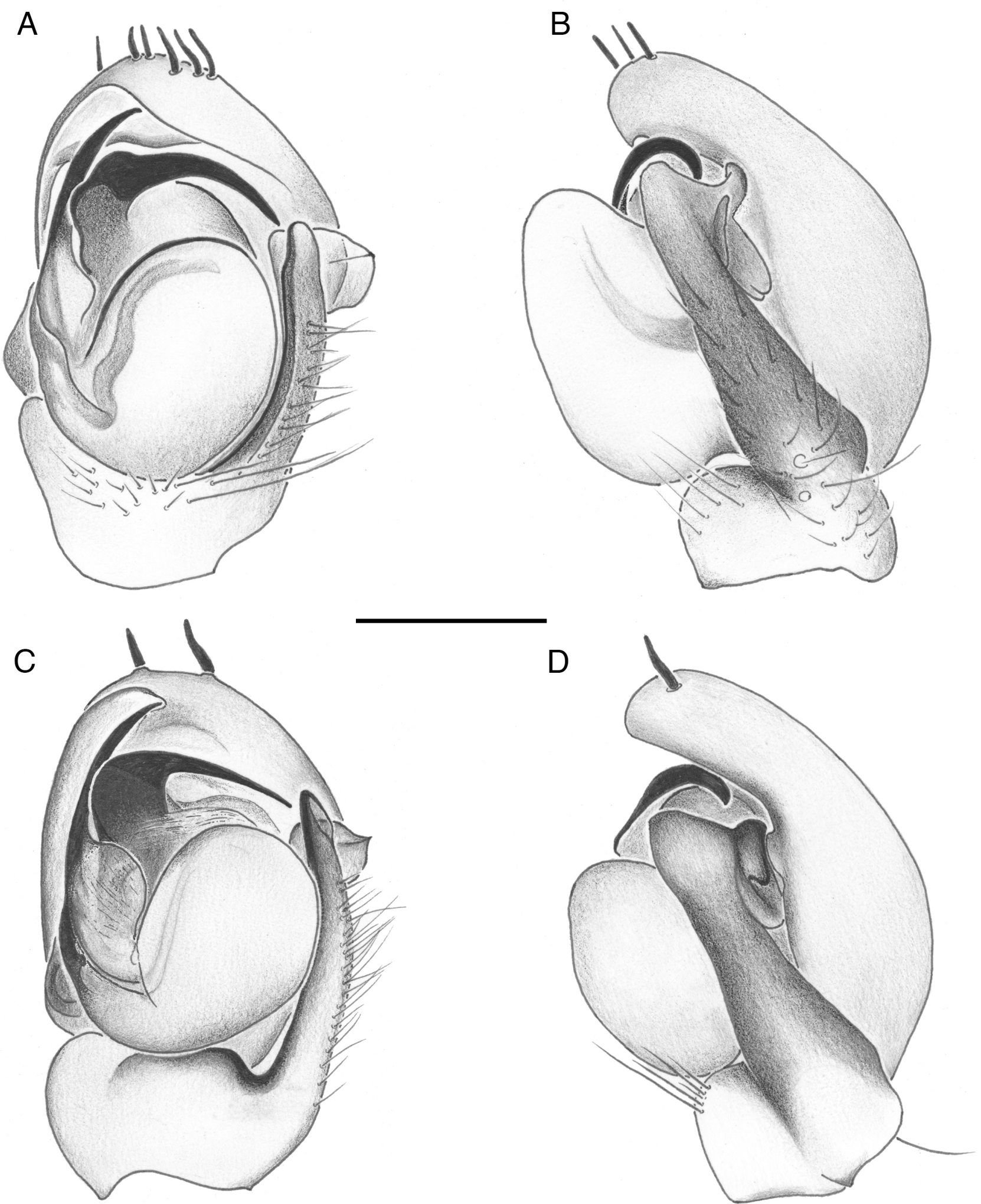

Fig. 19. Cicynethus subtropicalis (Lawrence, 1952) comb. nov., male palps. A-B. NCA 2007/303. C-D. NCA 2016/842. A, C. Ventral views. B, D. Retrolateral views. Scale bar: 0.5 mm. 
Colour (Figs 15E, 16B-C). Very similar to colour of male.

STERnUm. Elongated oval, 1.63 wide, 2.56 long. All coxae with precoxal sclerites.

ChiLum. Poorly defined, two sclerites, each 0.10 high, 0.31 wide.

Eyes. ALE 0.21; AME 0.25; PLE 0.18; PME 0.16; ALE-AME 0.12; AME-AME 0.10; PLE-PME 0.25; PME-PME 0.13. Clypeus 0.38 high, with several long setae.

LEG MEASUREMENTS.

\begin{tabular}{ccccccc}
\hline & Fe & P & Ti & Mt & t & Total \\
\hline I & 4.13 & 1.61 & 3.08 & 2.45 & 1.61 & 12.88 \\
II & 2.94 & 1.47 & 2.94 & 1.61 & 1.33 & 10.29 \\
III & 2.38 & 1.33 & 1.40 & 1.05 & 1.05 & 7.21 \\
IV & 3.01 & 1.47 & 2.45 & 1.75 & 1.19 & 9.87 \\
\hline
\end{tabular}
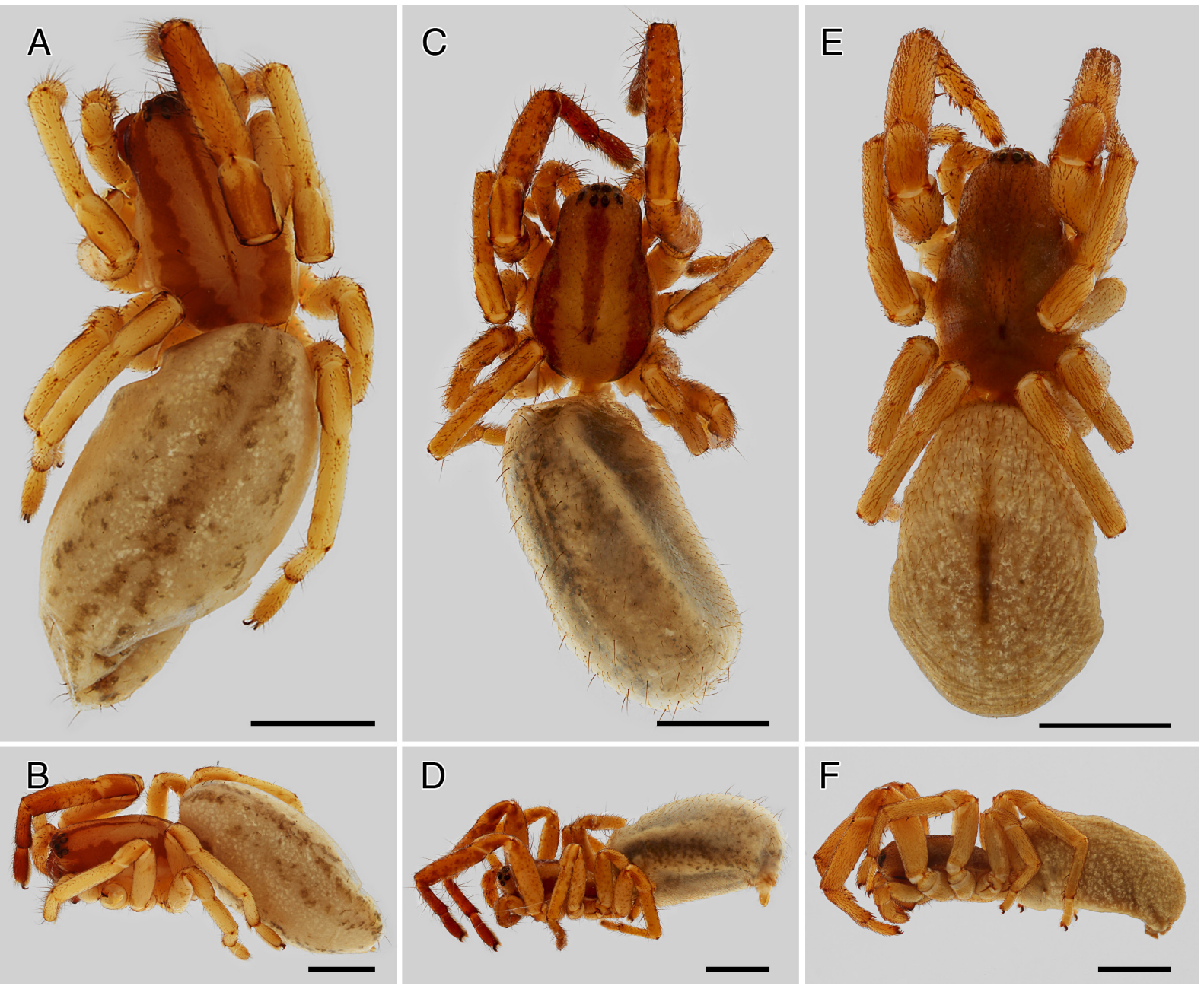

Fig. 20. A. Cicynethus cf. subtropicalis (Lawrence, 1952) comb. nov., + , subadult, dorsal view (Port Elisabeth, MNHN AR 10010). B. As preceding, lateral view. C. Cicynethus peringueyi Simon, 1910, holotype, subadult $q$ (MNHN AR 3293), habitus, dorsal view. D. As preceding, lateral view. E. Cicynethus acanthopus Simon, 1910, holotype, subadult + (MNHN AR 3290), dorsal view. F. As preceding, lateral view. Scale bars: $2 \mathrm{~mm}$. 
LEgs. Without hinged hairs. All Mt with four distal ventral spines in a series 1-2-1 with central ones closely set behind each other.

EPIGYNE (Fig. 17B). With wide posterior plate slightly procurved, in the middle produced into faint median septum delimiting large atria; large dark area on each side.

\section{Variation}

The colour of the live specimen (Fig. 15A-B) is quite aberrant from what is observed in specimens kept in ethanol (Fig. 15C-G). The carapace of the live specimen is almost uniform dark brown except for a small paler patch at the posterior margin, whereas in all the preserved specimens there is a clear pattern composed of three dark bands interrupted by stretches of medium brownish orange. Also, the abdominal pattern is somewhat different: the dorsolateral dark bands are less pronounced than in the collection specimens. Considering the locality where the live specimen was photographed, we assume that its colour pattern falls within the variation observed in the species, with the characteristic contrasting white posterior stretch of the median abdominal band (Fig. 15A-G). The epigyne is also subject to quite some variation, as shown in the pictures (Fig. 17A-F) and in the interpretation in the drawings $(17 \mathrm{G}-\mathrm{H})$. Details of the male palp also vary to some extent. The inclination of the palp may lead to rather different observations and interpretations, mainly in connection with the details of the RTA apex (Figs 18B, E, G, 19B, D) and the curvature of the median apophysis (Figs 18A, C, F, 19A, C). The distal swelling of the MA (Figs 18C, 19A) seems absent in Figs 18F and 19C, but this is merely the result of the inclination at which the specimens is photographed or drawn.

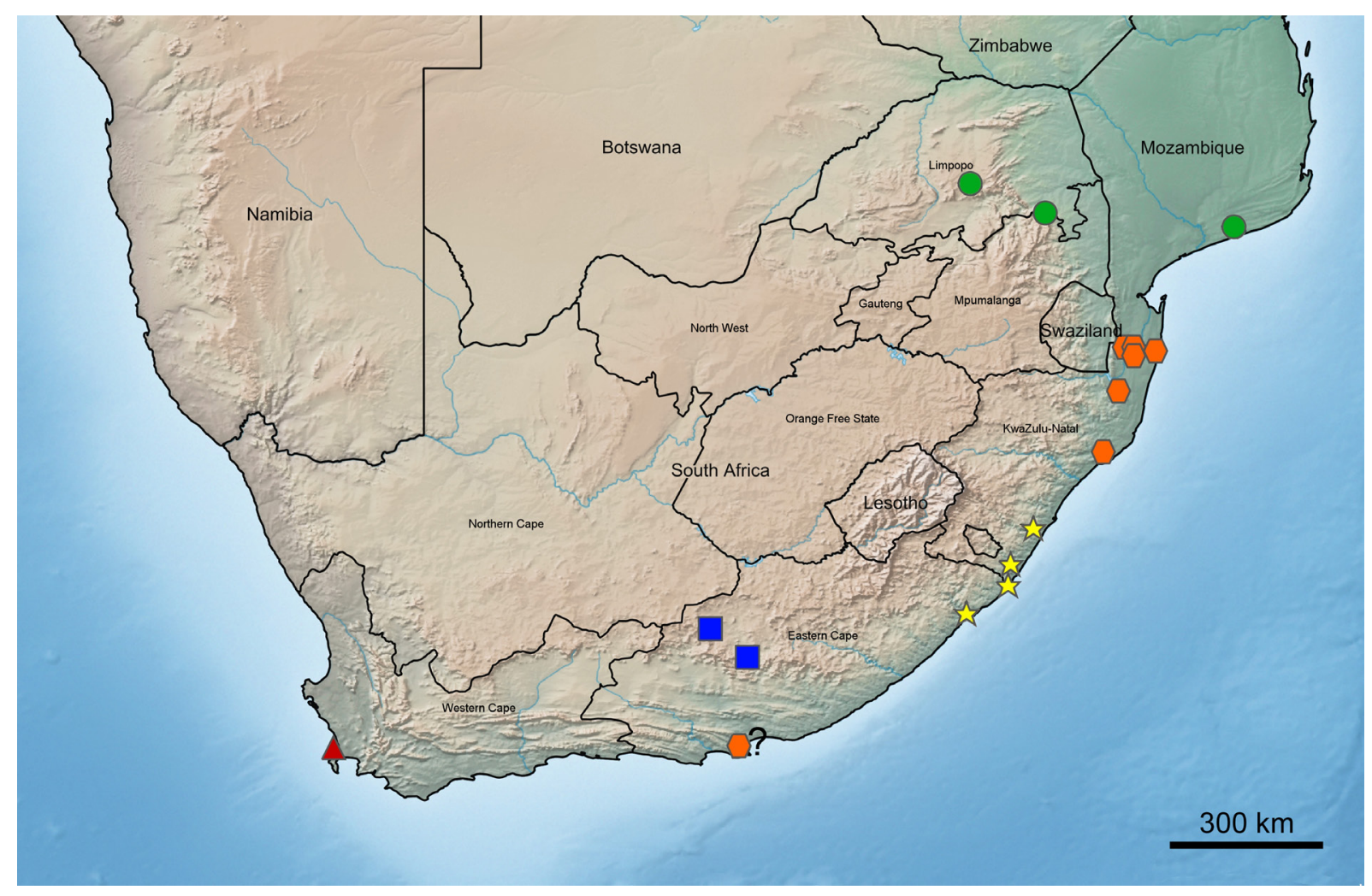

Fig. 21. Distribution map: Cicynethus acer sp. nov. (•); C. decoratus (Lawrence, 1952) comb. nov. ( $\star$ );

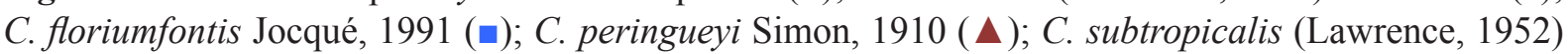
comb. nov. (๑). 
The female specimens from Empangeni (2000/438) have an epigyne in which the contours of the dark internal structure (Fig. 17E-F) look slightly different from those of the other specimens (Fig. 17A-D). However, since the colour pattern of all these specimens is similar and in the absence of males with different palps, we have refrained from describing another new species based on only two specimens.

\section{Distribution}

Known from several localities near the type locality in Kwazulu-Natal Province, South Africa (Fig. 21).

\section{Systematic notes}

Cicynethus acanthopus Simon, 1910, only known from a subadult female (Fig. 20E-F) from Namibia, is aberrant in many respects (see Jocque 1991): the shape and the setation of the carapace, the shape of the labium, the height of the clypeus and the leg spination. All these characters point in the direction of another genus, not yet identified. We therefore consider C. acanthopus as 'species incertae sedis'.

Cicynethus hongfuchui Barrion, Barrion-Dupo \& Heong, 2013 is not a member of Cicynethus and most probably an elongated species of Storenomorpha Simon, 1884. In that genus, the posterior eye row is strongly recurved, whereas it is clearly procurved in Cicynethus. The colour pattern and number

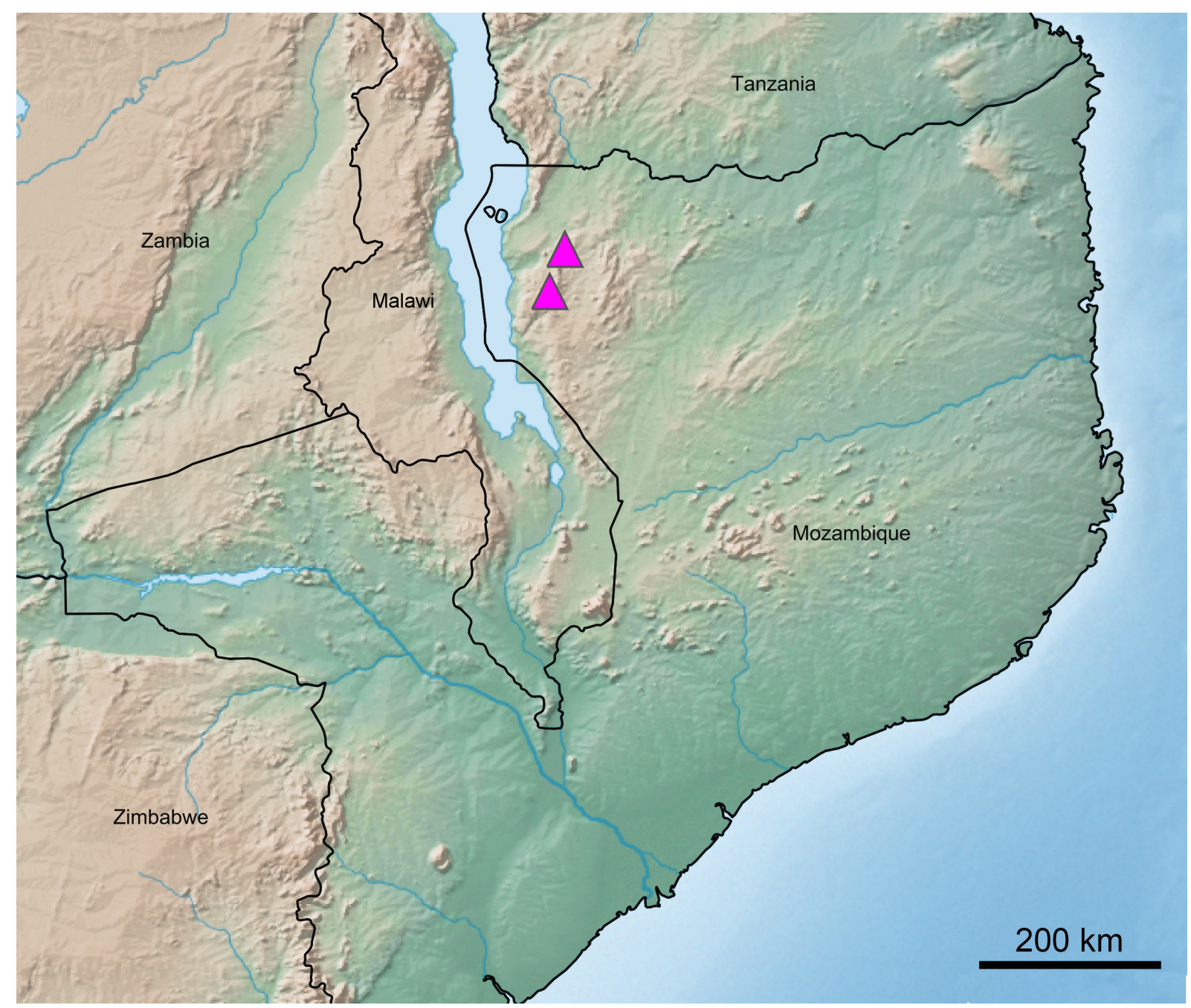

Fig. 22. Distribution of Cicynethus mossambicus sp. nov. ( $\mathbf{\Delta})$. 
of spines on the legs, very few in Cicynethus, also point to Storenomorpha. One character mentioned by Barrion et al. (2013: 45), "maxillae yellow except short black serrula", is puzzling because one of the synapomorphies of the family Zodariidae is the absence of a serrula. We here present the new combination Storenomorpha hongfuchui (Barrion, Barrion-Dupo \& Heong, 2013) comb. nov.

\section{Discussion}

The only specimen of C. peringueyi is a juvenile (Fig. 20C-D) from Cape Town and it remains questionable whether it belongs to one of the species described on adults. Its pattern resembles that of C. floriumfontis and it might thus be either a senior synonym of that species or a species that has never been collected again. The juvenile specimen from Port Elizabeth (MNHN AR 10010), on the other hand, has a pattern (Fig. 20A-B) that is reminiscent of that of C. subtropicalis comb. nov., but the locality falls completely outside its presently known distribution area and is even separated from it by that of C. decoratus comb. nov. Considering the collecting efforts in the framework of the SANSA inventory (Dippenaar-Schoeman et al. 2015), it is surprising that no specimens of Cicynethus have been found in the vicinity of the two localities of these juveniles or along the coast in between these.

The microhabitat preference of Cicynethus is far from clear and puzzling. It is remarkable that most samples are small and there is not a single sample in which adults of both sexes are present. The majority of the specimens have been found at ground level, either in pitfall traps or by sifting leaf litter. But, as could be expected, other specimens were found in Malaise traps, or by sweeping the shrub layer. Representatives of the Storenomorphinae are, indeed, expected to live in tube-shaped retreats above ground level (Jocqué \& Bosmans 1989; Leroy \& Jocqué 1993; Jocqué 1994). However, the frequency with which Cicynethus is found in pitfalls might indicate that they have a mixed life style and spend part of their life cycle at ground level and part in the shrub layer. According to C. Haddad (pers. comm.), juveniles are primarily litter-dwellers and adults tend to move to foliage. The experience with C. subtropicalis comb. nov. has been to find adults in low shrubs $(<1.5 \mathrm{~m}$ high $)$ only, where they construct a tubular retreat, sticking several broad leaves together with silk. This observation is in accordance with what can be deduced from some of the samples listed above.

This brings us to the colour pattern. There is one large sample $(\mathrm{n}=17)$ of $C$. decoratus comb. nov. in which both juveniles and one adult female are present (RMCA_ARA_131806). The colour pattern of the carapace of the juveniles is clearly different from that of the adult, which might point in the direction of a different life style. Yet, the colour pattern of the adults is apparently stable and clearly different between the species. This is quite unusual. Colour patterns are hardly ever used to a large extent to differentiate spiders living at ground level, and in the many revisions of Zodariidae, this character has been used only once, more precisely to differentiate some species in the key to females of Suffascar Henrard \& Jocqué, 2017 (Henrard \& Jocqué 2017: 533). Yet, in Cicynethus it is perfectly possible to combine the keys for males and females to identify the species almost solely on the base of their colour pattern. It was thus possible to identify the females from the Oribi Gorge Nature Reserve and Ingogo

Forest Reserve as $C$. decoratus comb. nov. Surprisingly, the terminology used in both descriptions (the present one was carried out independently from the one by Lawrence 1952), is fairly different. This illustrates the phenomenon that there is hardly a standardized terminology to describe colour patterns.

\section{Acknowledgements}

We are indebted to members of BINCO (Biodiversity Inventory for Conservation, BINCO.eu) for the material of C. mossambicus sp. nov. which was the key motive to start this revision. The BINCO expedition to Mozambique was supported by the Critical Ecosystem Partnership Fund (S16-367 Moz BINCO), Royal Geographical Society (with IBG) with a Neville Shulman Challenge Award, The Rift Valley Corporation and World Wildlife Fund Belgium. We thank curators at NMSA (John Midgley), 
NCA (Petro Marais, Ansie Dippenaar-Schoeman, Robin Lyle) and NMBA (Leon Lotz) for the loan of material. Alain Reygel is thanked for the drawings and Bennie Kruger for the picture of a live C. subtropicalis comb. nov. Charles Hadded made an important comment on the lifestyle of Cicynethus and made corrections to an earlier draft. Photographs of some spiders are available in the digital collections of the RMCA at http://digit03.africamuseum.be/home. This is publication number BRC 423 of the Biodiversity Research Center, Université Catholique de Louvain, Belgium.

\section{References}

Barrion A.T., Barrion-Dupo A.L.A., Catindig J.L.A., Villarreal S.C., Cai D., Yuan Q. H. \& Heong K.L. 2013. New species of spiders (Araneae) from Hainan Island, China. UPLB Museum Publications in Natural History 3: 1-103.

Brecko J., Mathys A., Dekoninck W., Leponce M., Vandenspiegel D. \& Semal P. 2014. Focus stacking: Comparing commercial top-end set-ups with a semi-automatic low budget approach. A possible solution for mass digitization of type specimens. Zookeys 464: 1-23. https://doi.org/10.3897/zookeys.464.8615

Dippenaar-Schoeman A.S., Haddad C.R., Foord S.H., Lyle R., Lotz L.N. \& Marais P. 2015. South African National Survey of Arachnida (SANSA): review of current knowledge, constraints and future needs for documenting spider diversity (Arachnida: Araneae). Transactions of the Royal Society of South Africa 70: 245-277. https://doi.org//10.1080/0035919X.2015.1088486

Henrard A. \& Jocqué R. 2017. The new ant-eating genus Suffascar (Araneae, Zodariidae) endemic to Madagascar: a considerable extension of the dual femoral organ clade. Invertebrate Systematics 31: 519-565. https://doi.org/10.1071/IS16064

Jocqué R. 1991. A generic revision of the spider family Zodariidae (Araneae). Bulletin of the American Museum of Natural History 201: 1-160.

Jocqué R. 1994. A termite mimicking spider: Thaumastochilus termitomimus n. sp. (Araneae, Zodariidae). Journal of African Zoology 108: 321-327.

Jocqué R. 2009. Some keep it short: on the radiation in the Afrotropical spider genera Capheris and Systenoplacis (Araneae, Zodariidae) without male pedipalp complexity increase. Journal of Afrotropical Zoology 5: 77-148.

Jocqué R. \& Bosmans R. 1989. A revision of the genus Storenomorpha Simon (Araneae, Zodariidae). Spixiana 12: 125-134.

Lawrence R.F. 1952. New spiders from the eastern half of South Africa. Annals of the Natal Museum 12: $183-226$.

Leroy A. \& Jocqué R. 1993. A note on the stitching habit of Chariobas sp. (Araneae, Zodariidae). Journal of African Zoology 107: 189-190.

Platnick N.I. \& Raven R.J. 2013. Spider systematics, past and future. Zootaxa 3683: 595-600. https://doi.org/10.11646/zootaxa.3683.5.8

Shorthouse D.P. 2010. SimpleMappr, an online tool to produce publication-quality point maps. Available from http://www.simplemappr.net [accessed 3 Jan. 2018].

Manuscript received: 21 April 2018

Manuscript accepted: 25 June 2018

Published on: 9 October 2018

Topic editor: Koen Martens

Desk editor: Kristiaan Hoedemakers 
JOCQUÉ R. \& HENRARD A., Revision of the genus Cicynethus Simon, 1910

Printed versions of all papers are also deposited in the libraries of the institutes that are members of the EJT consortium: Muséum national d'Histoire naturelle, Paris, France; Botanic Garden Meise, Belgium; Royal Museum for Central Africa, Tervuren, Belgium; Natural History Museum, London, United Kingdom; Royal Belgian Institute of Natural Sciences, Brussels, Belgium; Natural History Museum of Denmark, Copenhagen, Denmark; Naturalis Biodiversity Center, Leiden, the Netherlands; Museo Nacional de Ciencias Naturales-CSIC, Madrid, Spain; Real Jardín Botánico de Madrid CSIC, Spain; Zoological Research Museum Alexander Koenig, Bonn, Germany. 